\title{
The PROGINS polymorphism of the human progesterone receptor diminishes the response to progesterone
}

\author{
Andrea Romano ${ }^{1,2}$, Bert Delvoux ${ }^{1,2}$, Dagmar-Christiane Fischer ${ }^{1}$ and Patrick Groothuis ${ }^{1,2}$ \\ ${ }^{1}$ Department of Obstetrics and Gynaecology, ${ }^{2}$ Institute Growth and Development (GROW), University Hospital of Maastricht, Maastricht, The Netherlands \\ (Requests for offprints should be addressed to A Romano; Email: a.romano @ og.unimaas.nl)
}

(D-C Fischer is now at Department of Pediatrics, Experimental Nephrology, Rostock University Medical Centre, Rostock, Germany)

\begin{abstract}
The human progesterone receptor (PR) is a ligand-dependent transcription factor and two isoforms, (PRA and PRB), can be distinguished. PROGINS, a PR polymorphic variant, affects PRA and PRB and acts as a risk-modulating factor in several gynaecological disorders. Little is known about the functional consequences of this variant. Here, we characterise the properties of PROGINS with respect to transcription, mRNA maturation, protein activity and proliferation. PROGINS is characterised by a 320 bp PV/HS-1 Alu insertion in intron G and two point mutations, V660L in exon 4 and $\mathrm{H} 770 \mathrm{H}$ (silent substitution) in exon 5. The Alu element contains a half oestrogen-response element/Sp1-binding site (Alu$\mathrm{ERE} / \mathrm{Sp} 1$ ), which acts as an in-cis intronic enhancer leading to increased transcription of the PROGINS allele in response to $17 \beta$-oestradiol. Moreover, Alu insertions in the human genome are frequently methylated. Our data indicate that the PROGINS-Alu does not affect gene transcription due to DNA methylation. However, the Alu element reduced the stability of the PROGINS transcript compared with the CP allele and does not generate splice variants. The amino acid substitution (V600L) in exon 4 leads to differences in PR phosphorylation and degradation in the two PR variants upon ligand binding, most likely as a result of differences in the three-dimensional structures of the two PR variants. As a consequence, the PR-L660 (PROGINS) variant (1) displays decreased transactivation activity in a luciferase reporter system and (2) is less efficient in opposing cell proliferation in hamster ovarian cells expressing human PRA, when compared with the PR-V660 (most common variant). Taken together, our results indicate that the PROGINS variant of PR is less responsive to progestin compared with the most common PR because of (i) reduced amounts of gene transcript and (ii) decreased protein activity.
\end{abstract}

Journal of Molecular Endocrinology (2007) 38, 331-350

\section{Introduction}

Progesterone, together with $17 \beta$-oestradiol, is a key regulator of cell proliferation and differentiation in the female genital tract. Altered responses to oestrogen and progesterone lead to steroid hormone-dependent disorders like endometriosis, endometrial cancer, subfertility, breast and ovarian cancer.

All major actions of progesterone are mediated by the two progesterone receptor (PR) isoforms (PRA and PRB), which are ligand-dependent transcription factors (Beato \& Klug 2000, Li \& O’Malley 2003). PRB differs from PRA by the presence of 164 additional amino acids at the N-terminus. The remaining part is identical for both proteins and consists of the DNA-binding domain (DBD) and the C-terminal ligand-binding domain (LBD). A hinge region is located between DBD and LBD. This region is involved in nuclear translocation, dimerisation and cofactor binding, but its function in large part remains unclear (Beato \& Klug 2000, Li \& O'Malley 2003). After ligand binding and formation of hetero- or homodimers, PRA and PRB bind to progesterone-response elements (PRE) located in the promoter region of target genes and modulate their expression. Studies on cell lines (Richer et al. 2002) and animal models (Lydon et al. 1995, Mulac-Jericevic et al. 2000, 2003, Conneely et al. 2003) have shown that PRA and PRB have distinct functional activities.

The $P R$ gene, located on chromosome 11q22-23, comprises eight exons and seven introns $(A-G)$. One PR polymorphic variant, PROGINS (Rowe et al. 1995, Agoulnik et al. 2004) consists of a 320 bp PV/HS-1 Alu insertion in intron $G$ and two single nucleotide polymorphisms (SNPs). SNP-G3432T (mRNA nucleotide counting, NCBI: X51730) affects exon 4 and causes an amino acid substitution (V660L), whereas SNPC3764T affects exon 5 and is a silent mutation $(\mathrm{H} 770 \mathrm{H})$. These three aberrations are in complete linkage disequilibrium (De Vivo et al. 2002, Agoulnik et al. 2004, Schweikert et al. 2004, Pijnenborg et al. 2005) and a plethora of epidemiological studies indicate that PROGINS might modify the risk for several benign and malign gynaecological disorders (Dunning et al. 1999,

DOI: $10.1677 / j m e .1 .02170$ Online version via http://www.endocrinology-journals.org 
Lattuada et al. 2004, Modugno 2004, Schweikert et al. 2004, Pijnenborg et al. 2005, Romano et al. 2006). However, the results are not conclusive.

Considering the possible consequences of each of the three PROGINS aberrations, only the Alu insertion and the V660L amino acid substitution are expected to affect the function of the receptor. In fact, RNA processing is not influenced by the two SNPs (G3432T in exon 4 or the C3764T in exon 5). Preliminary algorithm analyses to predict the secondary structures of RNA transcripts containing the two PROGINS SNPs showed that neither RNA folding, nor the binding sites for ribonucleoprotein complexes involved in mRNA maturation are affected by these two SNPs. Furthermore, the silent mutation $(\mathrm{H} 770 \mathrm{H})$ is not expected to alter the properties of the PR protein. Several authors have indicated that $\mathrm{Alu}$ insertions can be of functional relevance with respect to $\mathrm{CpG}$ islands DNA methylation, gene transcription and binding of transcription factors (Deininger \& Batzer 1999, Gibbons \& Dugaiczyk 2005) and the generation of splice variants due to Alu exonisation (Deininger \& Batzer 1999, Lev-Maor et al. 2003, Sorek et al. 2004). Thus, the intron G Alu insertion could affect transcription and pre-mRNA maturation, including splicing, whereas the V660L amino acid substitution could only affect the activity of the protein.

Given that PROGINS occurs at frequencies up to $0 \cdot 15$ in Caucasians of different origins, the functional characterisation of this polymorphism is important to clarify its role in the pathogenesis. To this end, we have investigated the individual consequences of the two most likely relevant gene and protein aberrations associated with the PROGINS, the intronic Alu insertion and the V660L amino acid substitution, with respect to their effects on RNA maturation, protein activity and proliferation using different in vitro approaches.

In the following part of this study, the most common polymorphic allele or protein variant (i.e. no Alu insertion and V660) will be indicated as CP allele or protein.

\section{Materials and methods}

\section{Cell lines}

Human cervical cancer cell line HeLa, human ovarian cancer cell lines MDAH:2774 and Skov-3, human breast cancer cell lines T47D and MCF7 and Chinese hamster ovarian cell line CHO-K1 were purchased from the American Type Culture Collection (ATCC; Rockville, MD, USA). With the exception of T47D cells, none of the cell lines mentioned above express the PR. MCF7 cells are homozygous PROGINS, whereas T47D cells are heterozygous. The remaining cell lines are homozygous CP. Cells were maintained in Roswell Park memorial Institute medium (RPMI; Invitrogen Life Technologies, Inc.) supplemented with $10 \%$ foetal bovine serum
(Hyclone, Gent, East Flanders, Belgium), $2 \mathrm{mM}$ L-glutamine, $2 \mathrm{mM} \mathrm{Na}$ pyruvate, $100 \mathrm{U} / 1$ penicillin and $100 \mathrm{mg} / 1$ streptomycin).

\section{Steroid hormones}

Progesterone, org2058 and the antagonists (RU486 or org31710) were a gift from Organon NV (Oss, Brabant, The Netherlands). 17 $\beta$-Oestradiol and tamoxifen were purchased from Sigma-Aldrich Chemie BV. All hormones were dissolved in ethanol at a stock concentration of $10^{-3} \mathrm{M}$.

\section{Oligonucleotides}

Oligonucleotides used for PCR amplification were purchased from MWG-Biotech AG (Ebersberg, Bayern, Germany) and are listed in Table 1.

\section{Plasmids}

Plasmid for the expression of the reporter gene $\beta$-galactosidase (pSV- $\beta$-galactosidase) was purchased from Promega GmbH. PR-responsive reporter plasmid MMTV-luciferase (MMTV-LUC; Muller et al. 2000) was a gift from Prof. Schuele. Expression plasmids for PRAV660 (CP), PRA-L660 (PROGINS protein variant), PRB-V660 and PRB-L660 (Agoulnik et al. 2004) were based on plasmid pcDNA3.1 (Invitrogen Life Technologies, Inc.), and were kindly provided by $\mathrm{Dr}$ Agoulnik. Minigenes for the expression of PRA-IntGCP, PRB-IntG-CP and PRA-IntG-Alu, PRB-IntG-Alu were constructed by re-inserting the complete intron $G$ derived either from the CP allele (2672 nucleotides) or from the PROGINS (2992 nucleotides) allele at its original genomic position in the cDNAs of PRA and PRB. The complete intron $G$ was cloned by PCR in four steps from genomic DNA isolated from cell lines Skov-3 (CP homozygous) and MCF7 (PROGINS homozygous) as templates. The Expand High Fidelity Kit (Roche) was used for PCR as recommended by the manufacturer. A detailed description of all cloning steps is given in Fig. 1. Figure 2A shows the structure of the intron $\mathrm{G}$ and relevant restriction sites used for cloning.

Plasmids used for transfections were prepared using the Qiaquick Plasmid maxi KIT (Qiagen GmbH). Plasmid concentration was determined spectrophotometrically and by agarose gel electrophoresis.

\section{Stable and transient transfection}

Stable transfection of CHO-K1 cells with either one of the plasmids encoding PRA-V660, PRB-V660, PRA-L660 or PRB-L660 were performed using jetPEI (Q-Biogene, Heidelberg, Baden-Württemberg, Germany) as 
Table 1 Oligonucleotides and their applications

Name

PR-GA-FW

PR-GA-RV

PR-GB-FW

PR-GB-RV

PR-GC-FW

PR-GC-RV

PR-GD-FW

PR-GD-RV

Exon-4 S

Exon-4 AS

Exon-5 AS

RSF-3

RSF-4

CycloA S

CycloA AS

PROGINS-I

PROGINS-II

Alu-Ex-RV

PS2-0

PS2-1

PS2-2

PS2-3

ChIP-pos-FW

ChIP-pos-RV

ChIP-neg-FW

ChIP-neg-RV

Alu-ERE-Sp1-FW

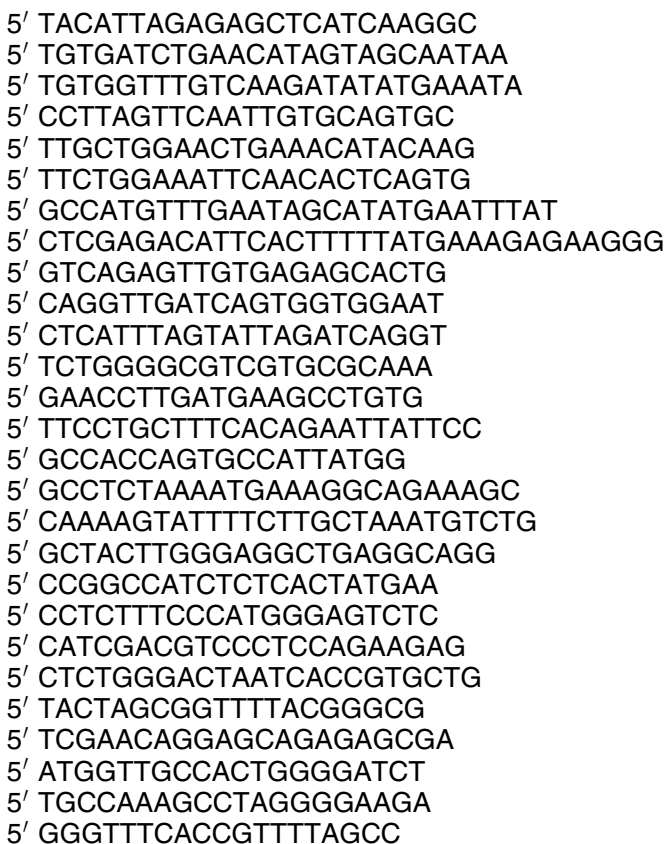

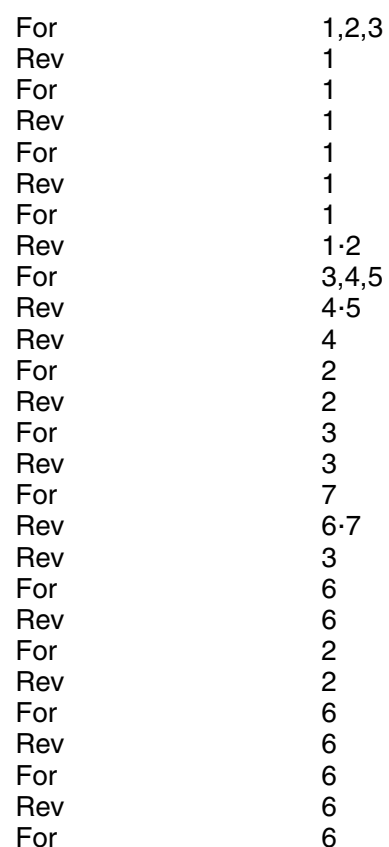

Applications: 1, cloning of intron G; 2, cDNA quantification; 3, Alu exonisation analysis; 4, RFLP on gDNA; 5, RFLP on cDNA; 6, ChIP; 7, detection of PV/HS Alu element in the gDNA. For/Rev, forward or reverse primer.

recommended by the manufacturer. For the selection of stably transfected clones, transfected cells, as well as their untransfected counterpart, were plated in RPMI supplemented with $5 \mathrm{mg} / 1$ blasticidin-S-HCl (Invitrogen, Life Technologies, Inc.) 3 days after transfection. After 2 weeks of incubation with blasticidincontaining medium, only transfected cells were viable. Monoclonal cells resistant to blasticidin were obtained by plating serial dilutions $(0 \cdot 01-10$ cells/well) on 96 well plates, isolating those colonies derived from a single cell (evaluated by microscopic observation) and subsequent sub-cloning of those clones that showed PR expression (western blotting). Cell lines derived from transfection with plasmid PRA-V660 were labelled CHO-A series, PRB-V660 lines CHO-B, PRA-L660 lines CHO-C and PRB-L660 lines CHO-D. Transient transfection of HeLa, MDAH:2774, Skov-3 and MCF7 cells as well as of maternal and stably transfected $\mathrm{CHO}-\mathrm{K} 1$ was performed using jetPEI (Q-Biogene) as recommended by the manufacturer.

\section{Genomic DNA (gDNA) extraction}

One million cells were lysed in $300 \mu \mathrm{l}$ DNA cell lysis buffer (200 mM Tris-HCl (pH 8•0), $250 \mathrm{mM} \mathrm{NaCl,} 25 \mathrm{mM}$
EDTA, $0.5 \%$ SDS). DNA was extracted with one volume of TE-equilibrated phenol (Amresco, Solon, Ohio, USA) and precipitated with 0.7 volumes of isopropanol. Genotype screening of the mutation V660L substitution was performed by PCR-RFLP using primers exon- $4 \mathrm{~S}$ and exon-4 AS (Pijnenborg et al. 2005). The presence of the $320 \mathrm{bp} \mathrm{PV/HSAlu} \mathrm{insertion} \mathrm{in} \mathrm{intron} \mathrm{G}$ was diagnosed by PCR using primers PROGINS-I and PROGINS-II (WangGohrke et al. 2000).

\section{RNA extraction and cDNA synthesis}

RNA was isolated using the Trizol reagent (Invitrogen, Life Technologies, Inc.) as recommended by the manufacturer. cDNA was synthesised using the M-MLV reverse transcriptase (Invitrogen, Life Technologies, Inc.) and poly-T oligonucleotide (MBI Fermentas GmbH, St Leon-Rot, Baden-Württemberg, Germany) for priming. Five micrograms of total RNA were used for cDNA synthesis. Prior to cDNA synthesis, RNA was treated with 3 U DNaseI (MBI Fermentas GmbH). To check the expression of the PR gene, semi-quantitative RT-PCR was performed using primers PR-GA-FW and PR-GD-RV. Primer pairs exon-4 S/exon-4 AS as well as exon-4 $\mathrm{S} /$ exon-5 AS were used to estimate the relative expression 
A

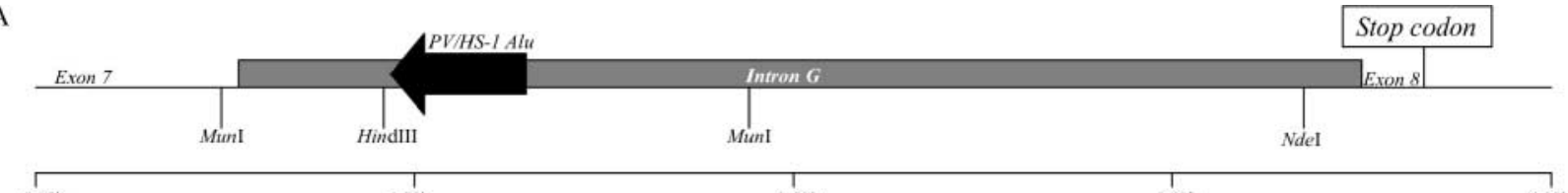

B

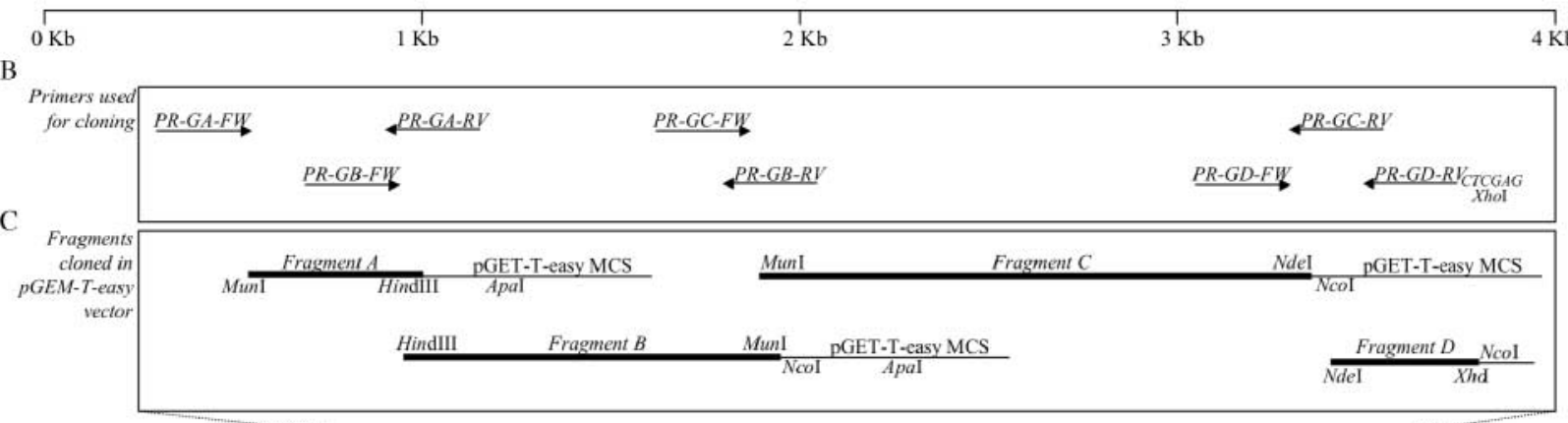

D

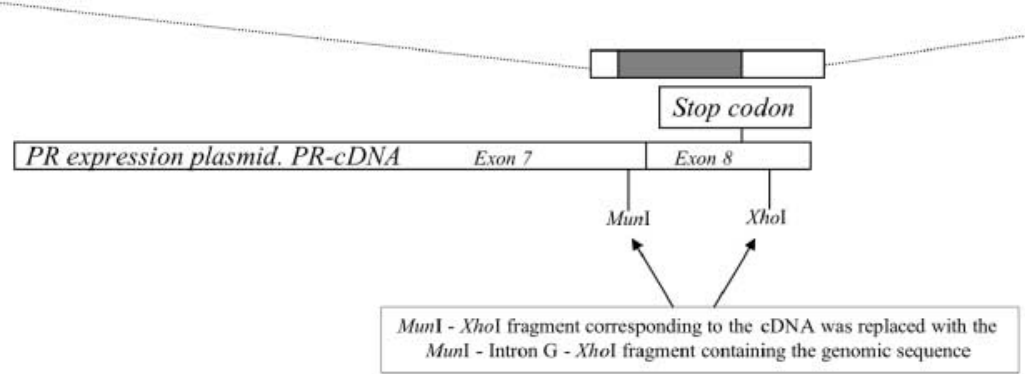

Figure 1 Scheme illustrating the cloning of the complete Intron $G$ into the minigenes. Minigenes for the expression of $P R A-I n t G-C P, P R B-I n t G-$ CP and PRA-IntG-Alu, PRB-IntG-Alu were constructed by re-inserting the complete intron G derived either from the CP (2672 nucleotides) or from the PROGINS (2992 nucleotides) allele at its original genomic position in the cDNAs of PRA and PRB (D). (A) Shows the complete intron G (grey bar) and the Alu insertion (black arrow). The direction of the arrow indicates the Alu sense orientation. Intron G was cloned by PCR in four steps from genomic DNA isolated from cell lines Skov-3 (CP homozygous) and MCF7 (PROGINS homozygous) as templates. The four fragments of the intron $\mathrm{G}$ generated in the cloning strategy are shown in (C). The Expand High Fidelity Kit (Roche) was used for PCR as recommended by the manufacturer. Primers used to amplify corresponding fragments are shown in (B) and sequences are given in Table 1 . Fragment A (747 nucleotides), common to both CP and PROGINS alleles, was amplified using primers PR-GA-FW and PR-GA-RV. Fragment A contained the $3^{\prime}$ end of exon 7 including the Munl restriction site and contained at its $5^{\prime}$ the HindllI restriction site present in intron G. Munl and HindIII were used for subsequent cloning. Fragment B was amplified using primers PR-GB-FW and PR-GB-RV. Fragment B contained HindIII and Munl restriction sites (both present in intron $\mathrm{G}$ ) at the $5^{\prime}$ and $3^{\prime}$ respectively used for subsequent cloning. Fragment $B$ contained the site of the Alu insertion, thus it was amplified from Skov-3 (636 nucleotides) and MCF7 (956 nucleotides) genomic DNA in order to generate the CP and the PROGINS version of intron G fragment $B$. Fragment $C$ (1603 nucleotides), common to both CP and PROGINS alleles, was amplified using primers PR-GC-FW and PR-GC-RV and overlapped the $3^{\prime}$ of fragment B containing the Munl restriction site. At the $3^{\prime}$, fragment $C$ contained the Ndel restriction site. Fragment $D$ (336 nucleotides) was finally cloned using primers PR-GD-FW and PR-GD-RV. Fragment D overlapped the 3 end of fragment $C$ (including the Ndel restriction site) and contained at its $3^{\prime}$ end the complete exon 8 including the stop codon and followed by the Xhol restriction site (introduced by primer PR-GD-RV (B)). Xhol was present in the expression plasmid containing the PR cDNA and it was located downstream the cDNA stop codon (D). Fragments A-D were extracted from agarose gels using the Qiaquick gel extraction kit (Qiagen $\mathrm{GmbH}$ ), treated with $1 \mathrm{U}$ Taq DNA polymerase in presence of dNTPs (1 mM each; MBI Fermentas $\mathrm{GmbH}$ ) for $30 \mathrm{~min}$ at $72{ }^{\circ} \mathrm{C}$ in the recommended buffer containing $\mathrm{MgCl}_{2}$ (MBI Fermentas $\mathrm{GmbH}$ ) and cloned into pGEM-T-easy plasmid (Promega GmbH, Mannheim, Germany) as recommended by the manufacturer. All plasmids were checked by sequence analysis (Ex-Dye terminator, as recommended by the manufacturer and ABI prism sequencer, Genome Center Maastricht). All pGEM-T-easy fragments A-D were selected having the desired orientation since subsequently cloning steps required unique restriction sites present in MCS of pGEM-T-easy. In step 1, fragment $C$ was excised using Munl (intron G) and Ncol (MCS of pGEM-T-easy) and cloned into Munl/Ncol sites of pGEM-T-easy fragment B-CP and pGEM-Teasy fragment B-PROGINS. Step 2: fragment D was isolated by Ndel/Ncol (MCS) double digestion and cloned into the Ndel (intron G; partial digested)/Ncol (MCS) sites of pGEM-T-easy fragments B-C (wild type and PROGINS). Step 3: fragments B-D, wild type and PROGINS, were isolated by digestion with HindIII (intron G) and Apal (MCS) and cloned into HindllI/Apal sites of pGEM-T-easy fragment A. Thus, fragments A$D$ corresponded to the complete intron $G$ sequence flanked by part of exon 7 (containing the Munl restriction site) and by the complete exon 8 (including stop codon and Xhol site downstream). Step 4: the complete intron G-exon 8 fragment (containing the wild type and the PROGINS intron $\mathrm{G}$ ) were subsequently excised using Xhol/Munl partial digestion and cloned into Xhol (MCS on pcDNA3.1 expression plasmid)/Munl of PRA-V660, PRB-L660 and yielding PRA-IntG-CP, PRB-IntG-CP and PRA-IntG-Alu, PRB-IntG-Alu. All restriction endonucleases were purchased from MBI Fermentas $\mathrm{GmbH}$ and used as recommended by the manufacturer. Conditions for Ndel and Munl partial digestions were determined empirically. All regions of the plasmids where ligations took place were checked by sequence analysis. 


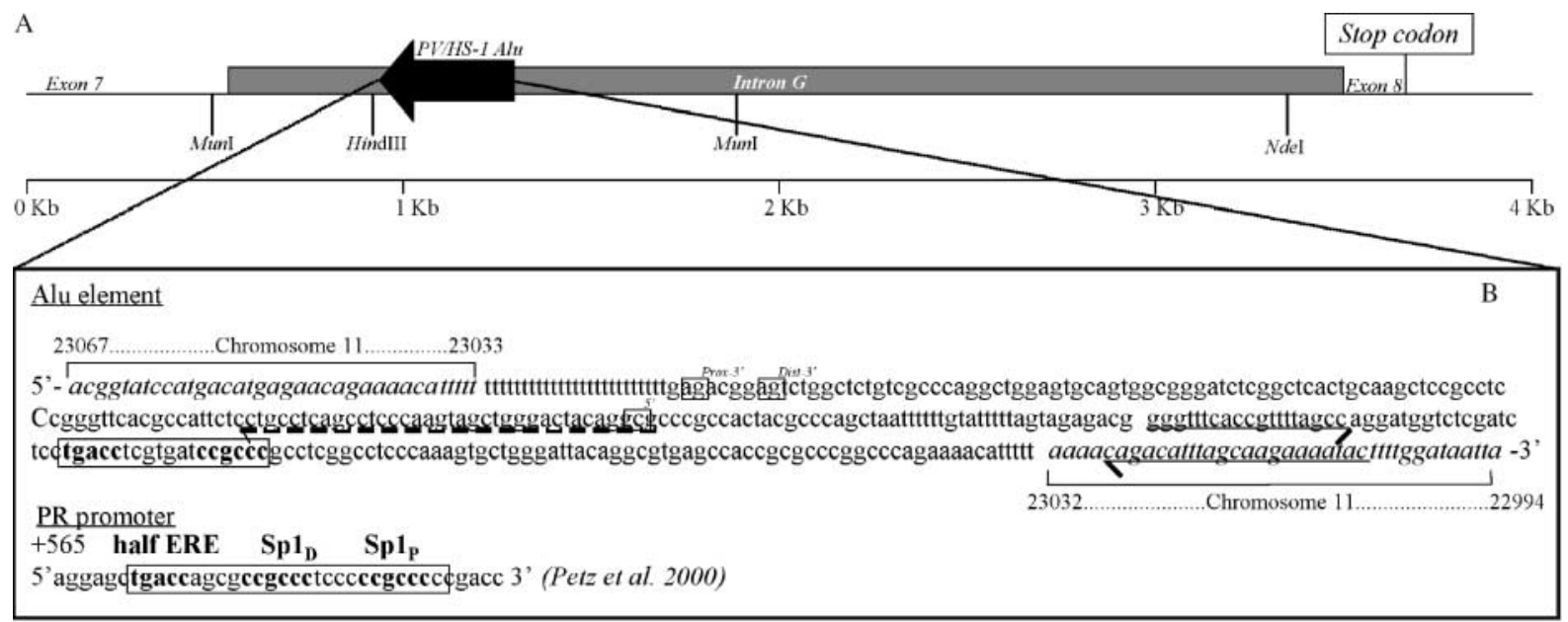

C

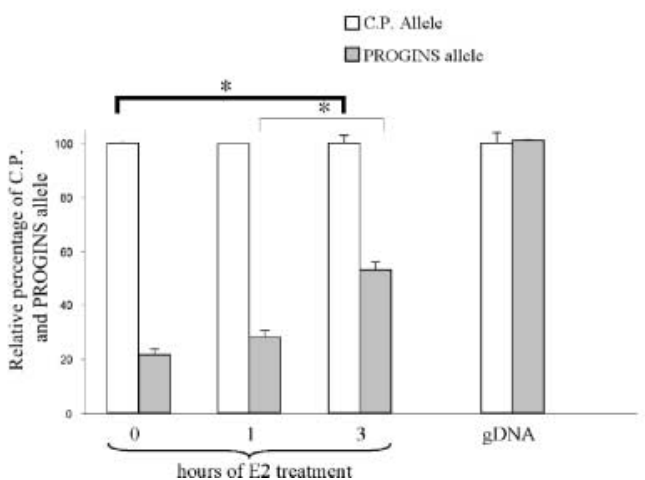

D

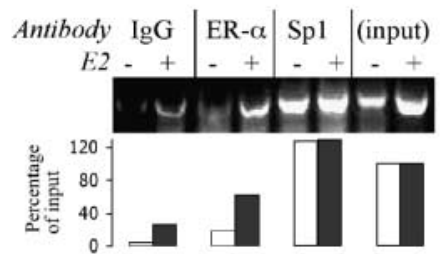

Figure 2 ER- $\alpha$ and Sp1 bind to the PROGINS Alu and enhance transcription of the PROGINS allele. (A) Structure of the PROGINS intron $G$. The Alu element is indicated as an arrow whose direction shows the sense orientation of the element. Relevant restriction sites used for cloning of intron G into the PR minigenes (see Fig. 1) are indicated. (B) The sequence of the Alu insertion in intron G of the PROGINS allele is shown at the top. Genomic sequences flanking the Alu insertion are in italics (chromosome 11 numbering; NCBI NC000011). The sequence of the PR promoter comprising the half-ERE/Sp1 site (Petz \& Nardulli 2000) is shown at the bottom (numbering based on the PR mRNA; NCBI X51730). The Alu-ERE/Sp1 and the half-ERE/Sp1-binding sites are in bold and squared. Primers used for ChIP (Alu-ERE-Sp1-FW and PROGINS-II) are underlined with solid line arrows. Putative $3^{\prime}$ and $5^{\prime}$ splice sites are boxed, and reverse primer specific for the Alu-exonised splice variant (Alu-Ex-RV) is dashed-underlined. (C) Treatment of T47D cells with $17 \beta$-oestradiol $\left(E 2,10^{-8} \mathrm{M}\right.$ ) for 1 and $3 \mathrm{~h}$ increases the relative abundance of CDNA (mRNA) derived from the PROGINS allele (grey bars) compared with the CP (white bars). The abundance of the transcripts is evaluated by quantifying the intensities of the bands visible in an agarose gel generated after PCR-RFLP on CDNA. The ratio of PROGINS and CP cDNA is normalised by comparison with the band intensities obtained from PCR-RFLP on genomic DNA (gDNA) that is considered to represent equimolarity of the CP and PROGINS alleles and the total amount of PR CP transcript is fixed to 100. Values represent the average ( \pm S.D., bars) of two independent experiments each consisting of three replicates. Asterisks indicate $P<0.05$ ( $t$-test). Given the small variations observed, the results were confirmed in two extra independent experiments. (D) ChIP analysis on T47D with ER- $\alpha$ and Sp1 antibodies indicates binding of these transcription factors to the Alu-ERE/Sp1 site. Chromatin-protein complexes were crosslinked after 50-min incubation with vehicle or $17 \beta$-oestradiol $\left(10^{-8} \mathrm{M}\right.$; E2). Crosslinked chromatin was immunoprecipitated (IP) with negative control (IgG), with ER- $\alpha$ antibodies (F10) or Sp1 antibodies. A region of intron G containing the Alu-ERE/Sp1 site was amplified by PCR (primers underlined with solid line arrows in (B). ChIP results were reproduced in three independent experiments. As a positive control of the ChIP procedure, binding of RNA Pol-II (antibody 4H8) to the GAPDH promoter and binding of ER- $\alpha$ to the oestrogen-responsive-PS2 promoter were assessed (not shown). Input: sheared chromatin used for ChIP procedure.

of CP PR and PROGINS alleles by utilising PCR-RFLP analysis on cDNA. For Alu exonisation, forward primer PR-GA-FW or exon-4 $\mathrm{S}$ was used in combination with the reverse primer Alu-Ex-RV. Expression of the oestrogenresponsive $P S 2$ gene was investigated with primer pair pS2-2/pS2-3. Expression of the RASSF1 gene was evaluated using primers RSF-3 and RSF-4. For PCR normalisation, expression of the cyclophilin A gene (housekeeping) was analysed using CycloA S/CycloA AS for amplification of the corresponding cDNA.

\section{Chromatin immunoprecipitation (ChIP)}

ChIP was performed as described elsewhere (Shang et al. 2000). Briefly, T47D cells were cultivated to $80 \%$ 
confluence $\left(75 \mathrm{~cm}^{2}\right.$ culture flasks) in RPMI without phenol red (Invitrogen, Life Technologies, Inc.) supplemented with $10 \%$ hormone-stripped serum (c.c.pro $\mathrm{GmbH}$, Neustadt, Saxony, Germany) for 3 days. Cells were treated with vehicle (ethanol) or with $17 \beta$-oestradiol $\left(10^{-8} \mathrm{M}\right)$ for $50 \mathrm{~min}$. Subsequently, cells were fixed (RPMI with $1 \%$ formaldehyde, $10 \mathrm{~min}$ at $37^{\circ} \mathrm{C}$ ) washed twice with cold PBS and scraped in $1 \mathrm{ml}$ cold PBS supplemented with Complete protease inhibitor (Roche). Cells were lysed in $10 \mathrm{mM}$ HEPES (pH 6.5), $10 \mathrm{mM}$ EDTA, $0 \cdot 25 \%$ Triton X-100 supplemented with complete protease inhibitor. Nuclei were pelleted and subsequently lysed in $300 \mu \mathrm{l}$ lysis buffer ( $1 \%$ SDS, $10 \mathrm{mM}$ EDTA, $50 \mathrm{mM}$ Tris-HCl (pH 8.1) plus Complete protease inhibitor) and sonicated. Debris was pelleted, aliquots of the nuclear lysates $(50 \mu \mathrm{l})$ were diluted ten times in immunoprecipitation (IP) buffer (1\% Triton, $2 \mathrm{mM}$ EDTA, $150 \mathrm{mM} \mathrm{NaCl}, 20 \mathrm{mM}$ Tris- $\mathrm{HCl}(\mathrm{pH} 8 \cdot 1)$ ) and pre-cleared $\left(2 \mathrm{~h}, 4^{\circ} \mathrm{C}\right)$ with $100 \mu \mathrm{l}$ protein-G beads (Active motif, Rixensart, Brabant, Belgium). For IP of chromatin-protein complexes, specific antibodies $(2 \mu \mathrm{g})$ were added and the tubes were continuously rotated during incubation (overnight, $4^{\circ} \mathrm{C}$ ). For IP of ER- $\alpha$, RNA Pol-II and Spl-containing chromatin complexes, antibodies F10 (Santa Cruz Biotechnology, Santa Cruz, CA, USA), 4H8 and Sp1 (Active motif) were used respectively. Antibodies bound to chromatin complexes were precipitated by the addition of protein- $G$ beads $\left(100 \mu \mathrm{l}, 2 \mathrm{~h}, 4^{\circ} \mathrm{C}\right)$. Beads were washed six times $(100 \mathrm{mM}$ Tris-HCl (pH 8.0) containing $500 \mathrm{mM} \mathrm{LiCl}, 1 \% \mathrm{NP}-40$, $1 \%$ deoxycholic acid) and chromatin-protein complexes were eluted from the beads with $100 \mu \mathrm{l} 25 \mathrm{mM} \mathrm{NaHCO}_{3}$ supplemented with $1 \%$ SDS. Crosslinking was reversed by the addition of $4 \mu 15 \mathrm{M} \mathrm{NaCl}$ supplemented with $10 \mathrm{U}$ RNaseA and incubation overnight at $65^{\circ} \mathrm{C}$. Subsequently, the samples were treated with proteinase- $\mathrm{K}(400 \mathrm{mg} / \mathrm{l})$ in $20 \mathrm{mM}$ Tris- $\mathrm{HCl}(\mathrm{pH} 6.5)$ and $10 \mathrm{mM}$ EDTA for $2 \mathrm{~h}$ at $42^{\circ} \mathrm{C}$ and DNA was purified using the Qiaquick reaction cleanup kit (Qiagen $\mathrm{GmbH}$ ). Binding of the RNA Pol-II to the GAPDH promoter was used as positive control of the ChIP procedure, and it was assessed using primers ChIPpos-FW and ChIP-pos-RV. ER- $\alpha$ binding to the PS2 promoter was used as a positive control for ChIP with ER- $\alpha$ and it was assessed using primers PS2-0 and PS2-1. For ER- $\alpha$ and Sp1 binding to the Alu-ERE/Sp1 site, primers Alu-ERE-Sp1-FW and PROGINS-II were used (Table 1 and Fig. 2B). ChIP PCR signals were normalised with an unspecific negative control, using primers ChIPneg-FW and ChIP-neg-RV that flank cytogenetic location 12 p13.3 where no transcription factors bind to.

\section{5-aza-2' -deoxycytidine (ADC) treatment}

Cells were plated in six-well plates at $50 \%$ confluence and treated for $0,48,96$ and $120 \mathrm{~h}$ with $100 \mu \mathrm{M}$ ADC (Sigma-Aldrich Chemie BV). ADC causes DNA demethylation. At the end of the treatment, RNA was isolated as described earlier. Medium containing ADC was refreshed every $24 \mathrm{~h}$.

\section{RNA stability assay}

Native T47D cells or MDAH:2774 cells transiently transfected with the PR minigenes were plated in sixwell plates at $70 \%$ confluence. One day later, actinomycin-D (Sigma-Aldrich Chemie BV) as an inhibitor of RNA synthesis was added to the medium $(6 \mu \mathrm{M}$ final concentration) and cells were cultured for the indicated period of time prior to isolation of RNA.

\section{Immunocytofluorescence}

Cells were cultured on glass coverslips (six-well plates, overnight) and subsequently fixed in buffered formaldehyde (4\% paraformaldehyde in PBS). Cells were washed with PBS and permeabilised with $0 \cdot 1 \%$ Triton $\mathrm{X}-100$ diluted in PBS. To reduce unspecific binding, cells were incubated with PBS containing $1 \%$ BSA and $1 \%$ goat serum ( $1 \mathrm{~h}$, room temperature). To detect PR expression, cells were incubated with the PR-specific antibody AB-52 (Santa Cruz Biotechnology). Bound antibody was visualised using Cy-3-labelled goat antimouse antibodies (Jackson Immunoresearch, Cambridge, UK).

\section{Transactivation assay}

Cells were cultivated for at least 3 days in RPMI without phenol red (Invitrogen, Life Technologies, Inc.) supplemented with $10 \%$ hormone-stripped serum (c.c.pro $\mathrm{GmbH}$ ). One day before transfection, cells were plated in 12-well plates at $40-50 \%$ confluence. In each well, $1 \mu \mathrm{g}$ MMTV-LUC reporter plasmid, $800 \mathrm{ng}$ of either PR-L660, PR-V660 or pcDNA3.1 (empty vector; Invitrogen, Life Technologies, Inc.) together with $200 \mathrm{ng}$ pSV- $\beta$-galactosidase were co-transfected. In all experiments, $\beta$-galactosidase was used for normalisation of luciferase measurements with transfection efficiency. Twenty-four hours after transfection, the culture medium was replaced and supplemented with the ligand as indicated in Fig. 3. After an additional 24-h incubation, cells were lysed in $60 \mu 100 \mathrm{mM}$ Tris- $\mathrm{HCl}$ (pH 7.8), $0.5 \%$ Triton X-100 and $40 \mu \mathrm{l}$ extract were assayed for luciferase activity by adding one volume of Steady-GLO substrate (Promega GmbH). The remaining extract was used for $\beta$-galactosidase assay and western blot analysis. For $\beta$-galactosidase assay, 5-10 $\mu \mathrm{l}$ extract were incubated in 96-well plates with $180 \mu \mathrm{l}$ PBS supplemented with $0.7 \mathrm{mg} / \mathrm{ml}$ of $o$-nitrophenyl- $\beta$ galactopyranoside (Sigma-Aldrich Chemie BV) and $0.4 \% \quad \beta$-mercaptoethanol $\quad\left(2-4 \mathrm{~h}, \quad 37^{\circ} \mathrm{C}\right)$. 


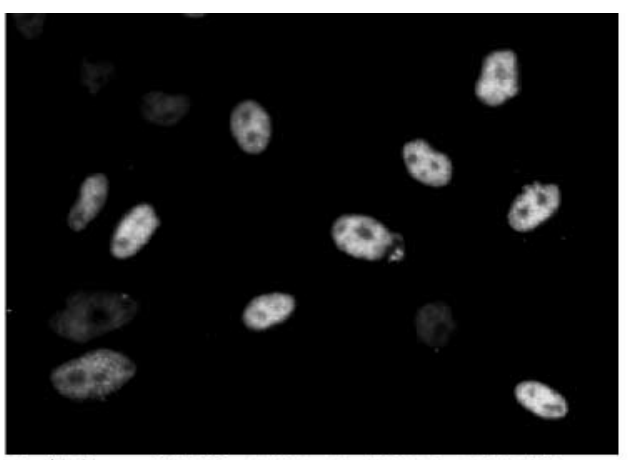

Cell line CHO-A25_2 (PRA-V660)

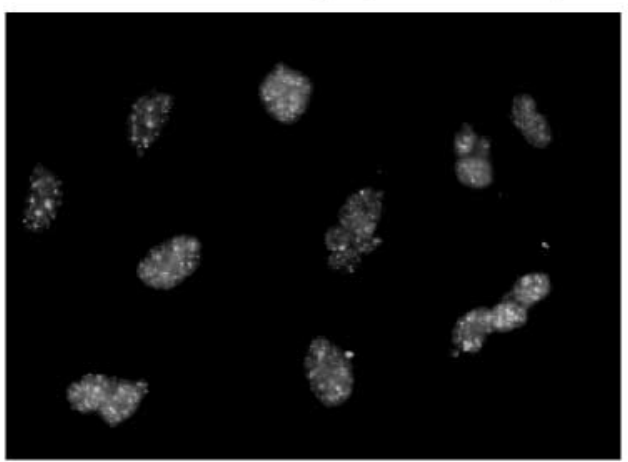

Cell line CHO-B34 (PRB-V660)

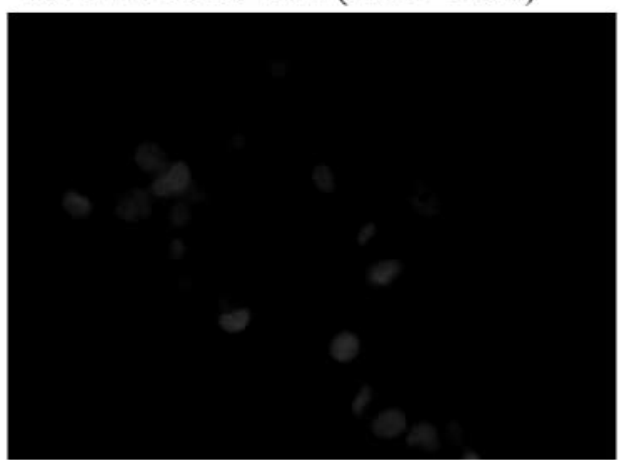

Cell line CHO-A21 (PR negative)

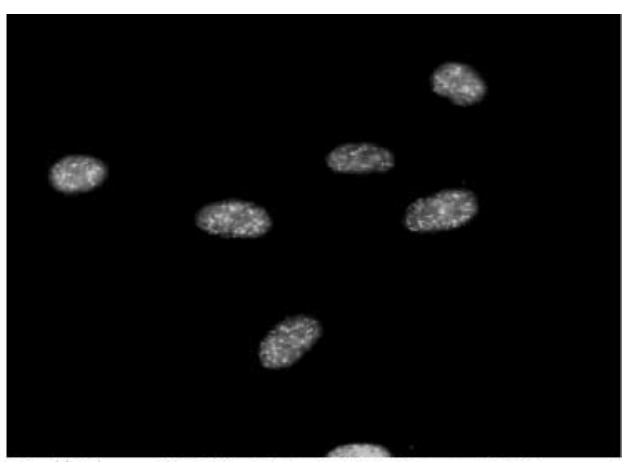

Cell line CHO-C4_3 (PRA-L660)

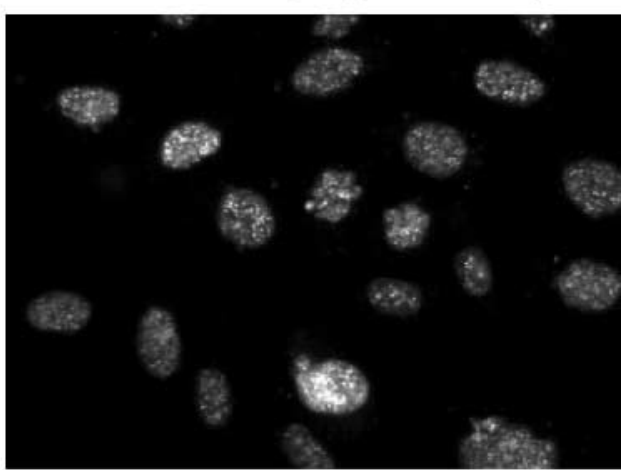

Cell line CHO-D9 14 (PRB-L660)

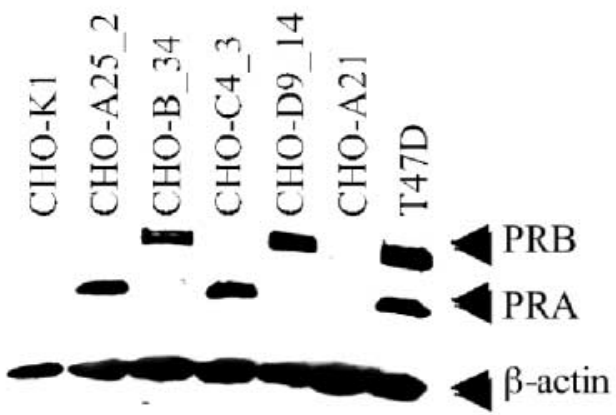

Figure 3 Characterisation of cell lines stably transfected with PRA and PRB. Immunocytofluorescence on cell lines CHO-A25_2, CHO-B34, CHO-C4_3, CHO-D9_14 and CHO-A21 stably expressing PRA-V660, PRB-V660, PRA-L660, PRB-L660 and PR negative respectively. Antibodies raised against PR (AB-52) were used. At the bottom right: western blot analysis using antibody $A B-52$ (PR) on the same cells plus the maternal line $\mathrm{CHO}-\mathrm{K} 1$ and a positive control (T47D cells) to show the expression of equal amounts of PR in the selected lines. Expression of $\beta$-actin (antibody AC-15) was used as loading control.

$\beta$-Galactosidase activity was measured spectrophotometrically at $450 \mathrm{~nm}$. For western blot, replicates from one single experiment were pooled and western blot was performed as described below. Each data point was tested in triplicate using multiple plasmid preparations of PR-expressing constructs and significance of results was confirmed in at least two independent experiments.

\section{Trypsin digests}

Variations in the three-dimensional structure of a protein can be visualised by partial trypsin digests. Changes in the tertiary structure potentially mask or expose cutting sites for trypsin, which is known to cut after the amino acid arginine. Cells stably expressing PRA-V660 (CHO-A25_2), PRB-V660 (CHO-B34), 
PRA-L660 (CHO-C4_3) and PRB-L660 (CHO-D9_14) were induced in vitro with vehicle (ethanol) or ligand (progesterone $10^{-8} \mathrm{M}$ or RU486 $10^{-8} \mathrm{M}$ ) for $1 \mathrm{~h}$. Cell extracts were prepared in PBS and hormone induction was continued for $20 \mathrm{~min}$ at room temperature in silico with the same ligand used in vitro. Equal amounts of extracts $(20 \mu \mathrm{l})$ were incubated for $10 \mathrm{~min}$ at room temperature with increasing amounts of trypsin (from 0 to $25 \mu \mathrm{g} / \mathrm{ml}$ and 0 to $5 \mu \mathrm{g} / \mathrm{ml}$ for PRA and PRB respectively). Reactions were stopped by adding the SDS-PAGE loading dye and boiling immediately. The total volume was used for western blot analysis for PRA and PRB using antibody AB-52. Trypsin (Sigma-Aldrich Chemie BV) was dissolved in water.

\section{Preparation of protein extracts and western blot}

Cells were washed with cold PBS and lysed in RIPA buffer (10 mM sodium phosphate ( $\mathrm{pH} 7 \cdot 0$ ), $150 \mathrm{mM} \mathrm{NaCl}$, 2 mM EDTA, $1 \%$ Na deoxycholate, $1 \%$ NP-40 and $0 \cdot 1 \%$ SDS) supplemented with Complete protease inhibitor (Roche). Proteins were separated by SDS-PAGE (7-10\% polyacrylamide) and blotted on a nitrocellulose membrane (Protran, Schleicher and Schuell, Germany). PR was visualised using the AB-52 monoclonal antibody (Santa Cruz Biotechnology) or PR-A0098 polyclonal (Dako, Glostrup, Denmark). ER- $\alpha$ and Sp1 were visualised with antibody F10 (Santa Cruz Biotechnology) and Sp1 (Active motif) respectively. Antibody AC-15 (Sigma-Aldrich Chemie BV) was used to detect $\beta$-actin. For visualisation of bound antibodies, HRP-conjugated rabbit anti-mouse antibodies (DAKO, Netherlands BV, Eindhonen, Brabant, The Netherlands) and goat antirabbit antibodies (Pierce, Aalst, Flanders, Belgium) in conjunction with the super signal-R West-Femto kit (Pierce) were used. The proteasome inhibitor, MG132, was purchased from Biomol (Exeter, UK).

For determination of the protein concentration, the Bradford dye reagent (BCA assay; Uptima, Interchim, Montluçon, Allier, France) was used. Alkaline phosphatase was purchased from Fermentas $\mathrm{GmbH}$.

\section{Cell viability}

Cell viability, which is a measure for the total number of cells, was determined with the MTT assay (3-[4,5dimethylthiazole-2-yl] 2,5-diphenyl tetrazolium bromide (Sigma-Aldrich Chemie BV), as described previously (You et al. 2001).

\section{Cell proliferation}

Proliferative activity was assessed by determining 5-bromo-2-deoxyuridine (BrdU) incorporation. Cells were cultured for 3 days in RPMI without phenol red
(Invitrogen, Life Technologies, Inc.) supplemented with $10 \%$ hormone-stripped serum (c.c.pro $\mathrm{GmbH}$ ). Subsequently, cells were plated on six-well plates at $50 \%$ confluence and cells were synchronised by incubation for $20 \mathrm{~h}$ in RPMI (without serum) supplemented with nocadozole $(20 \mu \mathrm{g} / \mathrm{ml}$; Sigma-Aldrich Chemie BV). Cells were washed twice with PBS and cultured in RPMI supplemented with $10 \%$ hormone-stripped serum and containing $10 \mu \mathrm{M}$ BrdU (Sigma-Aldrich Chemie BV). Forty minutes after the addition of BrdU-containing medium, cells were fixed (in methanol) to measure the labelling index. Afterwards, cells were treated with org2058 or vehicle and fixed after 8,24 and $36 \mathrm{~h}$ of culture to measure BrdU incorporation. Fixation of cells and measure of the BrdU incorporation by flow cytometric analysis (FACSort Beckton and Dickinson, Sunnyvale, CA, USA) were performed as previously described (Schutte et al. 1997).

\section{Image quantification analyses}

For all agarose gel and western blot band quantification, the ImageJ programme was used (ImageJ 1.32j, Wayne Rasband, National Institutes of Health, USA, http://rsb.info.nih.gov/ij/).

\section{GenBank accession numbers}

PR mRNA accession number: NCBI X51730. PR mRNA G3432T and C3764T: NCBI AF016381. The accession number of the $P R$ partial gene and the Alu insertion into intron G is NCBI Z49816. SNP accession numbers: SNP-G3432T: Reference SNP Cluster Report (ref SNP ID): rs1042838; SNP-C3764T: ref SNP ID: rs1042839. Chromosome 11 complete sequence accession number is NC000011.

\section{Results}

\section{Consequences of the Alu insertion in intron G}

Mature mRNA does not contain the polymorphic intron G (with or without the Alu element). Nevertheless, the mRNA transcribed from the PROGINS allele can be distinguished from the $\mathrm{CP}$ transcript because it still contains the two SNPs in exon 4 (G3432T) and in exon 5 (C3764T) that are in linkage disequilibrium with the intronic Alu insertion. Using cell lines heterozygous for PROGINS, the relative abundance of the PROGINS and CP mRNAs (cDNA) can be assessed based on the PCRRFLP method used to diagnose the SNP in exon 4 in epidemiological studies (Pijnenborg et al. 2005; Fig. 4). For further analyses, the human breast cancer cell line T47D, which is heterozygous for PROGINS (Fig. 4A, lanes 

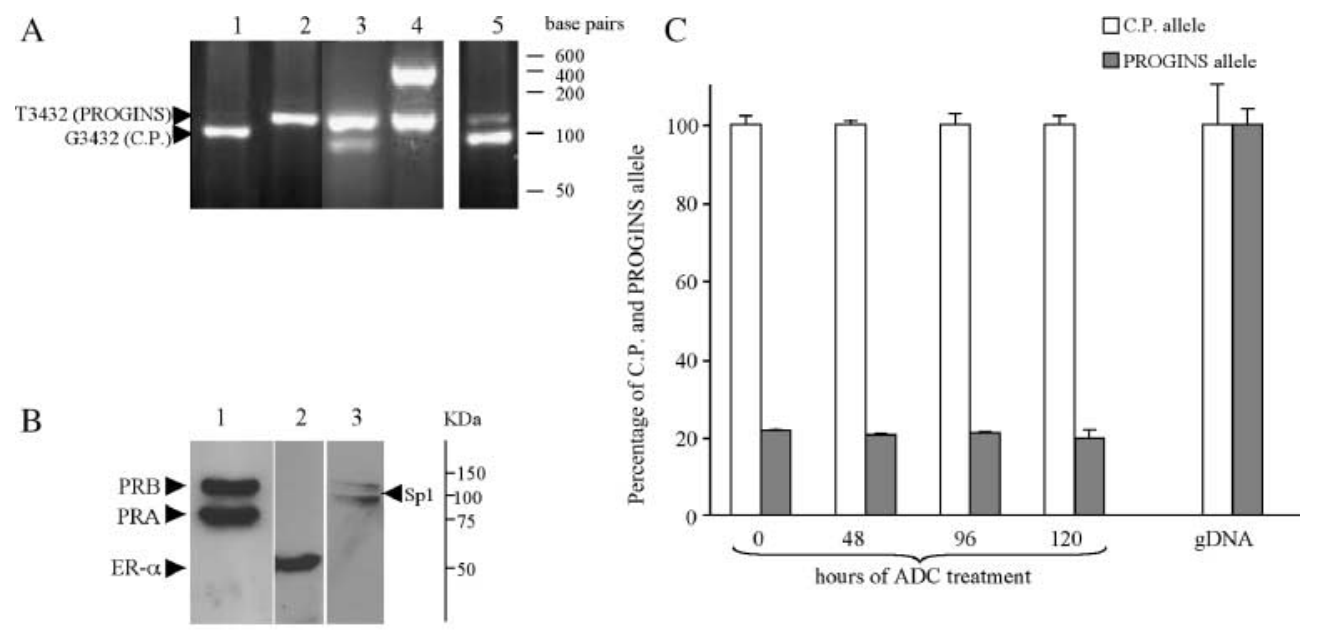

D

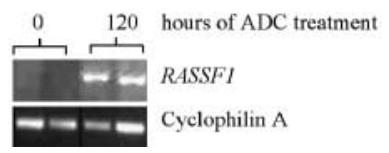

Figure 4 PR characterisation in cell line T47D and DNA demethylation. (A) Cell line T47D is PROGINS heterozygous. Lanes 1-3: PCR-RFLP analyses on genomic DNA (gDNA) to determine the G3432T substitution in exon 4 (primer pair exon-4 S and exon-4 AS (Pijnenborg et al. 2005)), which abolishes the $\mathrm{Brsl}$ restriction site. Upon Brsl digestion, PCR products derived from the CP allele (lane 1) generate one band of 95 nucleotides, whereas PCR products derived from the PROGINS allele generate one band of 115 nucleotides (lane 2). The presence of both bands (lane 3: cell line T47D) indicates heterozygosity for PROGINS. The upper band (indicating the PROGINS allele) has always a more intense staining compared with the CP band due to its bigger length (115 vs 95 nucleotides). The mutation in exon 4 (and exon 5 , not shown) is in linkage disequilibrium with the Alu insertion in intron G (De Vivo et al. 2002, Pijnenborg et al. 2005, Schweikert et al. 2004, Wang-Gohrke et al. 2000). The presence of the Alu insertion is directly diagnosed by PCR (primer pair PROGINS-I and PROGINS-II (Wang-Gohrke et al. 2000)) because its presence generates a PCR product of 496 nucleotides versus the product of 176 generated by the CP allele (lane 4 for cells T47D). To evaluate the relative abundance of PROGINS versus CP cDNAs in cells that are heterozygous for the PROGINS polymorphism (like T47D cells), the PCR-RFLP method can be applied to CDNA synthesised from these cells (lane 5). Ratios of band intensity can be normalised with the ratio obtained by PCR-RFLP on gDNA, which considered to represent a 1:1 molar ratio of the two alleles. For example, by comparison of lane 3 (T47D gDNA; CP: PROGINS =1:1) with lane 5 (T47D cDNA) it is evident that there is more CP transcript than PROGINS transcript in these cells. In all experiments involving this method, total RNA was treated with DNasel prior to CDNA synthesis. Furthermore, PCR products were always generated using primers annealing in exon 4 (Pijnenborg et al. 2005) and confirmed using PCR products that were obtained using one primer annealing on exon 4 and the second on exon 5 to exclude gDNA contaminations (as described in materials and methods; primer pair exon-4 S and exon-4 AS). (B) T47D cells express high level of PRA, PRB, ER- $\alpha$ and Sp1. Western blot analysis on cell extracts. Lane 1: PRA (90 kDa) and PRB (114 kDa) detected using antibody AB-52. Lanes 2 and 3: ER- $\alpha$ and Sp1 proteins detected with antibodies F10 and Sp1 respectively. (C) ADC treatment. The relative expression of the CP (white bars) and the PROGINS allele (grey bars) was evaluated by cDNA-PCR-RFLP after T47D cells were cultivated for the indicated period of time in the presence of ADC $(100 \mu \mathrm{M})$. Values are normalised with gDNA and the abundance of the CP allele is fixed to 100. Values \pm s.D. are based of triplicates measurements. (D) As a positive control for the ADC treatment, the expression of the RASSF1 gene, which is known to be heavily methylated in different breast cancer cell lines ((Dammann et al. 2001) and our laboratory, unpublished work), was evaluated by semi-quantitative PCR using primers RSF-3 and RSF-4.

3 and 4) and expresses the PR protein (Fig. 4B, lane 1), was selected.

\section{The PROGINS Alu insertion does not contain methylated $\mathrm{CpG}$ islands}

Alu elements have high CpG content that can be methylated and thus reduce gene transcription
(Deininger \& Batzer 1999). The PROGINS allele in cell line T47D is transcribed with reduced efficiency compared with the CP allele (Figs $4 \mathrm{~A}$, lane 5 and $4 \mathrm{C}$ ). To investigate whether this reduced transcription is due to CpG-Alu methylation, T47D cells were treated with ADC, which demethylates DNA. The relative expression of the PROGINS versus the CP allele was assessed by PCR-RFLP on cDNA and did not vary after ADC 
treatment for different periods of time $(0,48,96$ and $120 \mathrm{~h}$; Fig. 4C and D).

\section{The Alu element in intron $G$ increases in-cis the transcription of the PR-PROGINS allele}

The Alu element in intron $G$ of the PROGINS allele (Fig. 2A and B) contains the site TGA CCn nnn nnn CCG CCC (Alu-ERE/Sp1), located 1132 nucleotides downstream the $5^{\prime}$ splice site of intron $\mathrm{G}$. This site is similar to the half-ERE/Sp1 transcription site (Fig. 2B, bottom) located in the promoter region of the $P R$ gene and responsible for the oestrogen/Sp1-stimulated transcription of the $P R$ gene (Petz \& Nardulli 2000). We hypothesised that the Alu-ERE/Sp1 site may affect the transcription rate of the PROGINS allele. Since T47D cells express high levels of ER- $\alpha$ and Sp1 transcription factor (Fig. 4B, lanes 2 and 3), these cells were treated with $17 \beta$-oestradiol for different periods of time. Subsequently, the relative abundance of mRNA derived from the $\mathrm{CP}$ and the PROGINS alleles were assessed by cDNA-PCR-RFLP (Fig. 2C). After incubation with $17 \beta$-oestradiol $\left(10^{-8} \mathrm{M}\right)$ for 1 and $3 \mathrm{~h}$, the relative amount of PROGINS derived mRNA gradually increases from 21 to $53 \%$ compared with the mRNA derived from the C P. PRgene. Furthermore, ChIP indicated that ER- $\alpha$ and Sp1 bind to the Alu-ERE/Spl site (Fig. 2D). Whereas Sp1 transcription factor appears to bind independently of the presence of $17 \beta$-oestradiol, the binding of ER- $\alpha$ to this sequence is ligand dependent.

\section{The Alu element reduces the stability of the transcript}

Mobile elements like Alus transpose via a RNA intermediate that is transcribed by the RNA polymerase III (RNA Pol-III) and large differences have been reported on the stability of Alu RNAs belonging to different classes of Alu elements (Aleman et al. 2000, Li \& Schmid 2004). However, nothing is known on the influence that intronic Alu elements might have on pre-mRNAs, in which they are co-transcribed by the RNA Pol-II. The folding of the PR-pre-mRNA with or without the Alu insertion was predicted using the 'Vienna RNA Secondary Structure Prediction' algorithm (http://rna.tbi.univie.ac.at). Differences were seen in the free energies and the predicted structures of the two RNA molecules (not shown). To check whether these predicted differences affect the half-life of the corresponding RNAs, we compared the stability of the two PR transcripts in T47D cells (Fig. 5A). Cells were treated with actinomycin-D, an inhibitor of RNA synthesis. Three and eighteen hours of treatment with actinomycin-D $(6 \mu \mathrm{g} / \mathrm{ml})$ results in 50 and $80 \%$ decrease of the transcript generated from the PROGINS allele compared with the one generated from the CP allele. (Fig. 5B; The amounts of CP and PROGINS
cDNAs shown in the chart, do not represent the relative amount of the two molecules like in Figs 4 and 2, but are both fixed to 100 to clearly show the degradation rates.) To confirm that the observed trend was not a consequence of other known (such as SNPs in exons 4 and 5) or unknown genetic variations in linkage disequilibrium with the PROGINS-Alu insertion, human ovarian cancer MDAH:2774 cells (PR negative) were transfected with minigenes encoding the PR CP and PROGINS variant (PRA-IntG-CP, PRA-IntG-Alu, PRB-IntG-CP or PRB-IntGAlu). These minigenes, differing exclusively with respect to the presence of the Alu element in intron $G$, were correctly transcribed and translated (not shown). After the treatment of MDAH:2774 cells with actinomycin-D for $18 \mathrm{~h}$, we observed a reduction of approximately $20 \%$ of the amount of RNA generated from minigenes bearing the PROGINS intron G compared with the amount of RNA generated from minigenes expressing $\mathrm{PR}$ with the CP intron G (Fig. 5B). Although this reduction was less important compared with what we observed in T47D cells (see discussion for one possible explanation), it was seen for PRA and PRB.

\section{The PROGINS Alu insertion does not generate splice variants}

Alu elements contain $3^{\prime}$ and $5^{\prime}$ splice consensus sites (squared in Fig. 2B). When Alus are integrated into introns of actively transcribed genes, they can generate alternative splice variants by 'exonisation' of the approximately 100 nucleotides comprised between the $3^{\prime}$ and $5^{\prime}$ splice sites (Deininger \& Batzer 1999, Deininger et al. 2003, Lev-Maor et al. 2003, Sorek et al. 2004). To test whether the PROGINS Alu is 'exonised', cDNA from native cell line T47D and cell line Skov-3 or MDAH:2774 transiently transfected with the PR minigenes (PRA-IntGCP, PRA-IntG-Alu, PRB-IntG-CP or PRB-IntG-Alu) was analysed by PCR. When using primer pair overlapping the exon 7 /exon 8 boundary and annealing inside the PR coding sequence, no product larger than the correctly spliced PR cDNA was amplified. To further exclude the possibility that the cDNA form containing the 'exonised' Alu would not compete with the normally spliced PR cDNA because of too low expression, primers specific for the 'exonised' Alu were used (one primer, Alu-Ex-RV, anneals at the putative $5^{\prime}$ site for alternative splicing in the Alu element, underlined in Fig. 2B). However, no product could be amplified although the non-spliced PCR product derived from the minigene containing the complete intron $\mathrm{G}+$ Alu element could be efficiently amplified (not shown).

Taken together, on the one hand, the Alu insertion in intron $G$ moderately increases the transcription rate of the PR-PROGINS allele in response to $17 \beta$ oestradiol, while, on the other hand, the presence of the Alu element is accompanied by a decreased 
A
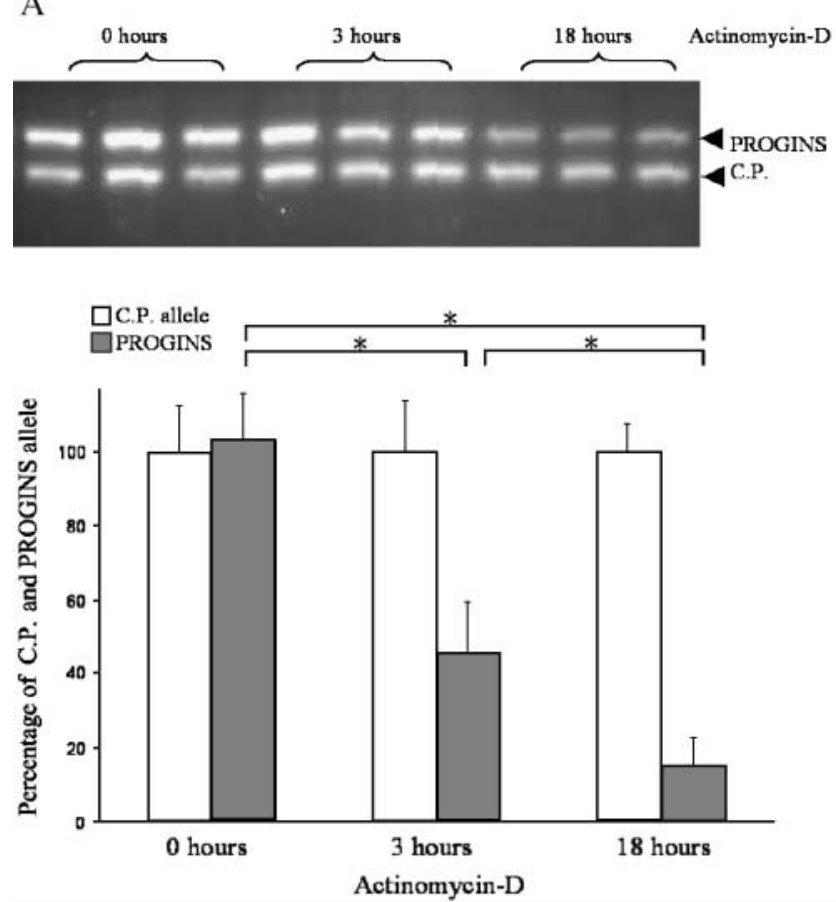

B
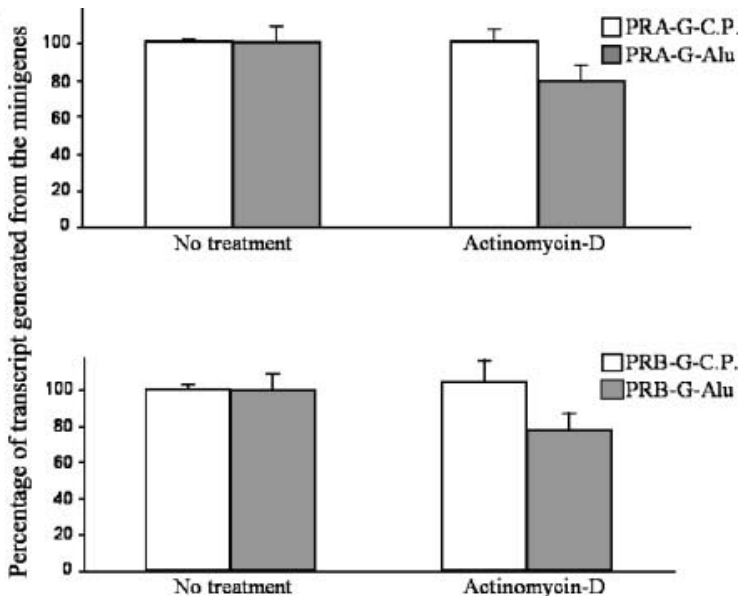

Figure 5 The Alu element reduces the stability of the PROGINS compared with the CP PR transcript. (A) The relative amount of cDNA derived from the CP and the PROGINS alleles was determined by PCR-RFLP on cDNA from T47D cells after treatment with actinomycin-D $(6 \mu \mathrm{g} / \mathrm{ml})$ for 0,3 or $18 \mathrm{~h}$. At the top, the agarose gel profile is shown and bands corresponding to the PROGINS and $\mathrm{CP}$ alleles are indicated. On the chart at the bottom, the amounts of CP (white bars) or PROGINS (grey bars) cDNAs are quantified from the PCR-RFLP profile. Bars do not indicate the relative molarity (i.e. gDNA normalisation) of the PROGINS and CP transcripts. The amount of both alleles is fixed to 100 with no actinomycin-D treatment. For the subsequent increasing periods of time of actinomycin-D treatments, the amount of transcript generated by the CP allele is fixed to 100, whereas the reduction in the amount of the transcript generated from PROGINS is shown. Mean values \pm s.D. are based of triplicate measurements. (B) MDAH:2774 cells (PR negative) were transfected with minigenes expressing either PRA-IntG-CP, PRA-IntG-Alu (top chart), PRB-IntG-CP or PRBIntG-Alu (bottom chart) and were treated for $18 \mathrm{~h}$ with actinomycin-D $(6 \mu \mathrm{g} / \mathrm{ml})$. The mRNAs transcribed from each minigene was quantified by semi-quantitative PCR using primer pair PR-GA-FW and PR-GD-RV. Values are normalised with cyclophilin A transcription (primer pair CycloA S and CycloA AS). The amount of transcript generated from minigenes without the Alu insertion (i.e. CP intron $\mathrm{G}$ ) is fixed to 100 for all actinomycin-D treatment, whereas the reduction in the amount of the transcript generated from minigenes containing the PROGINS intron G (fixed to 100 at time point 0 ) after treatment with actinomycin-D is shown. Mean values \pm s.D. are based on three or four replicates.

stability of the corresponding mRNA. No other effects related to the presence of the Alu insertion were detectable.

\section{Consequences of the V660L amino acid substitution in exon 4}

The following part of the study focuses on the consequences of the amino acid V660L substitution. Thus, when we refer to the PROGINS variant in this part of the study (both in the results and in the discussion sections), we consider exclusively the PROGINS protein variant characterised only by the leucine substitution at codon 660 , but we do not refer to the intronic Alu insertion.

\section{Generation of stably transfected cell lines}

Stably transfected CHO-K1 cells (Chinese hamster ovary) expressing PRA and PRB, CP (V660) and PROGINS protein variant (L660) were generated and four cell lines that had similar expression (western blot analysis and immunocytofluorescence; Fig. 3) of the V660 and L660 variants of PRA and PRB isoforms were selected: CHO-A25_2 (expressing PR-A V660), CHO-C4_3 (PR-A L660), CHO-B34 (PR-B V660) and CHO-D9_14 (PR-B L660). In cell line CHO-A21, the integration of the plasmid into the genomic DNA was confirmed by PCR but no PR expression was observed. Line CHO-A21, together with the maternal cell line CHO-K1, served as negative control. 


\section{Transactivation of PR PROGINS protein variant (L660) on an MMTV-luciferase reporter varies in a cell- dependent manner compared with the CP PR}

To determine whether the V660L substitution modifies the transactivation of PR, cells stably expressing PRA and PRB, V660 or L660 (see above) were transiently transfected with the MMTV-luciferase reporter plasmid. In addition, PR-negative cell lines derived from female gynaecological cancers (HeLa: human cervical cancer; Skov-3 and MDAH-2774: human ovarian cancer; MCF7: human breast cancer) were transiently transfected with equal amounts of PR expression plasmids along with the MMTV-luciferase reporter plasmid.

Progesterone-induced PRA leads to poor transactivation of the luciferase reporter gene (Fig. 6A). In HeLa and MCF7 cells (Fig. 6A), progesterone-induced PRAV660 and PRA-L660 equally reduce (approximately 20\%) luciferase activity compared with unligated receptor. On the contrary, in Skov-3 and in cells stably transfected with PRA (CHO-A25_2 and CHO-C4_3), progesterone
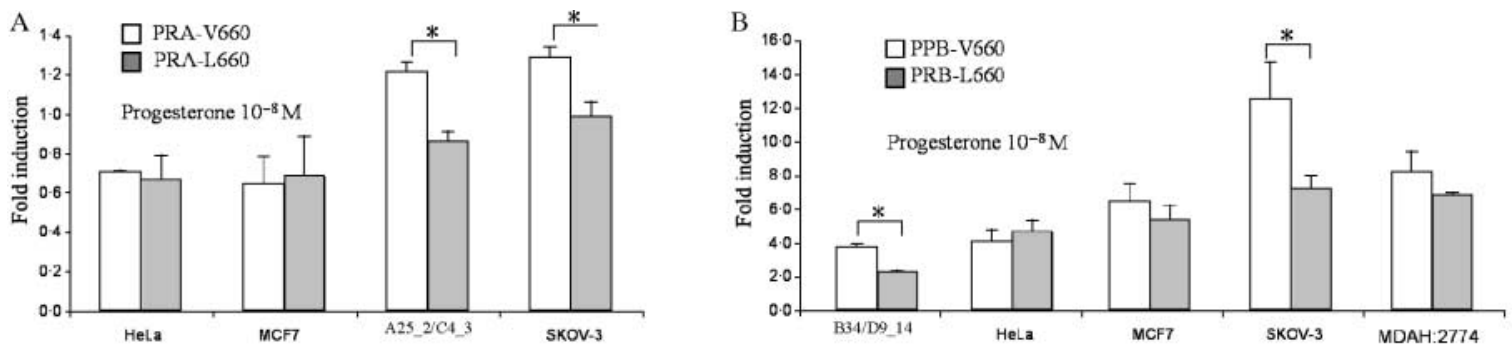

C

D
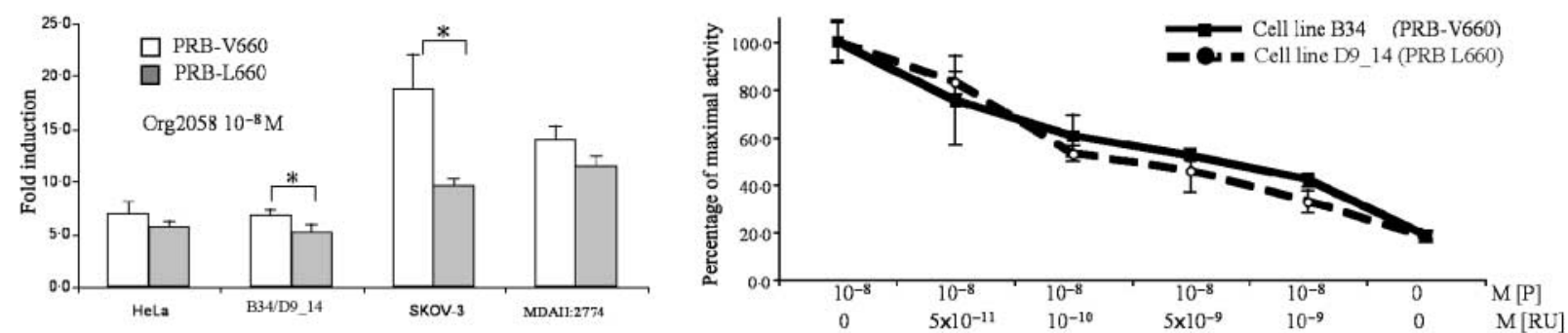

E

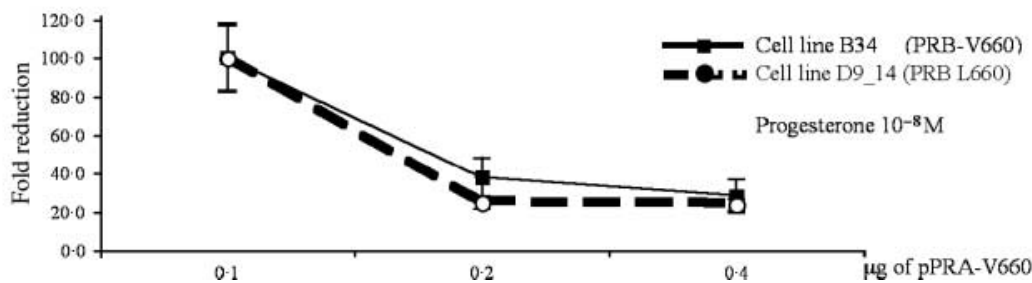

Figure 6 PR transactivation activity. Cell lines CHO-A25_2, CHO-B34, CHO-C4_3 and CHO-D9_14, stably expressing PRA-V660, PRB-V660, PRA-L660 and PRB-L660, were transiently transfected with MMTV-luciferase construct. In addition, cell lines HeLa, Skov-3, MDAH:2774 and MCF7 (all PR negative) were transiently transfected with equal amounts of PR expression plasmids along with MMTV-luciferase construct. Luciferase activity was measured $24 \mathrm{~h}$ after induction with different PR ligands, as indicated. Fold increase of luciferase activity obtained in the presence of ligand-activated receptor versus unligated receptor (treatment with vehicle alone) is shown. (A) Fold increase of the luciferase activity induced by progesterone $\left(10^{-8} \mathrm{M}\right.$ ) ligated PRA-V660 (white bars) or PRAL660 (grey bars) in the indicated cell line. (B and C) Fold increase of the luciferase activity induced by PRB-V660 (white bars) or PRBL660 (grey bars) after stimulation with $10^{-8} \mathrm{M}$ progesterone (B) or $10^{-8} \mathrm{M}$ org2058 (C) in the cell line indicated. (D) Titration curve of the antagonist RU486 $\left(R U ; 5 \times 10^{-11}-10^{-9} \mathrm{M}\right)$ in the presence of progesterone $\left(\mathrm{P} ; 10^{-8} \mathrm{M}\right)$ in Skov-3 cells transiently transfected with PRB-V660 (solid line) or PRB-L660 (dashed line) along with the MMTV-luciferase construct. For each antagonist treatment, the percentage of the maximal luciferase activity obtained with progesterone $\left(10^{-8} \mathrm{M}\right)$ and no RU486 is shown. (E) Cells stably expressing PRB-V660 (cell line CHO-B34, CP variant, solid line) or PRB-L660 (cell line CHO-D9_14, PROGINS, dashed line) were transiently transfected with increasing amounts of the PRA-V660 $(0.1,0.2$ and $0.4 \mu \mathrm{g})$ expression plasmid along with MMTVluciferase plasmid. Transactivation of progesterone $\left(10^{-8} \mathrm{M}\right)$ activated PRB on the MMTV-luciferase reporter construct was measured and the fold reduction of the luciferase activity is shown. Total amount of transfecting DNA was maintained constant using pcDNA3.1 (empty vector). Mean values \pm s.D. are based on three to four replicates. Significant results were repeated in independent experiments using different plasmid DNA preparations. Asterisks indicate a value of $P<0.05$ ( $t$-test). 
induction of PRA-V660 (CP PR) leads to a 1.2-fold increase of luciferase activity compared with unligated PRA-V660, whereas progesterone induction of PRA-L660 (PROGINS protein variant) does not change luciferase activity compared with the unligated receptor. Given that the expression of the receptor protein was confirmed by western blot analysis (not shown) we concluded that the reduced activity of PRA-L660 reflects a real functional consequence of the amino acid substitution.

Progesterone activation of PRB results in approximately 2- to 12-fold induction of luciferase activity (Fig. 6B) compared with the unligated receptor. PRB activated with the more potent agonist, org2058, leads to 5- to 20-fold induction of the luciferase activity (Fig. 6C). Large differences in the relative induction of luciferase activities are seen among cell lines. Transactivation activities of PRB-V660 and PRB-L660 are similar in HeLa, MCF7 and MDAH:2774 cell lines. However, similarly to what we observed for the PRA isoform, in Skov-3 and in cells stably expressing PRB (CHO-B34 and CHO-D9_14) ligand-bound PRB-L660 (progesterone, Fig. 6B and org2058, Fig. 6C) is significantly less active than ligand-bound PRB-V660 (CP receptor) on the MMTV promoter.

Titration of the antagonist RU486 in the presence of a fixed concentration of progesterone reveals no difference in transactivation activity of PRB-V660 and PRB-L660 (Fig. 6D). Similar results were obtained for all cell lines regardless of whether another antagonist (org31710) and agonist (org2058) were examined and for PRA as well (data not shown).

Transrepression is widely described among steroid hormone receptors and consists in the ability of one nuclear receptor to inhibit the activity of a second nuclear receptor. Given the crucial role of PRA, PRB and ER- $\alpha$ and their corresponding crosstalks, we investigated: (a) how the transactivation of either PRB isoform (V660 and L660), on the MMTV-luciferase is transrepressed by PRA (V660 or L660) and (b) how the transactivation of ER- $\alpha$ on an ERE-TK-luciferase reporter construct is influenced by PR (A or B isoform, V660/L660 variant). Transactivation of PRB on the MMTV-luciferase reporter gene is reduced by PRA in a dose-dependent manner (Fig. 6E). Transactivation of $17 \beta$-oestradiol-induced ER- $\alpha$ is reduced about $40-50 \%$ by PRA alone, PRB alone or by the presence of both receptors (data not shown). In the transrepression experiments (on PRB and on ER- $\alpha$ ), no differences between the CP and the PROGINS protein variant were observed.

\section{PRA and PRB PROGINS (L660) protein variants show different post-translational modifications compared with the CP PR-V660}

The V660L substitution does not affect DBD, LBD or activating functions (AF) of the PR. However, fine-tuning of PR activity is modulated by phosphorylation and protein degradation (Lange et al. 2000, Qiu \& Lange 2003, Qiu et al. 2003). We hypothesised that posttranslational modifications of PR may explain why the activities of the PROGINS protein variant compared with the CP PR differ in different cellular contexts. Cells stably transfected with PRA-V660 (CHO-A25_2), PRA-L660 (CHO-C4_3), PRB-V660 (CHO-B34) and PRB-L660 (CHO-D_14) were stimulated with different ligands and for different periods of time. Subsequently, cell extracts were analysed by western blotting to discriminate between non-phosphorylated and phosphorylated PR. Upon binding of an agonist (progesterone or org2058) or an antagonist (RU486, not shown), PRA and PRB are phosphorylated in a dosedependent manner (Fig. 7A and B), and this occurs regardless of V660 or L660. Phosphorylation occurs within $20 \mathrm{~min}$ after ligand induction and phosphorylated forms are still visible $24 \mathrm{~h}$ later. However, at this time point, PRB-V660 (CP) is more extensively phosphorylated after either agonist or agonist plus antagonist induction compared with PRB-L660 (PROGINS protein variant; Fig. 7C). The same trend, although less pronounced, is observed for PRA upon agonist induction but not after agonist plus antagonist induction (Fig. 7D).

Proteasomal-mediated protein breakdown of the PR protein starts a few hours after induction, regardless of whether an agonist or an antagonist is used. The involvement of the proteasomal machinery is shown for PRB by the decreased degradation seen after incubation with the proteasomal inhibitor MG132 (Fig. 7C). PRA-PROGINS protein variant (L660) appears to be degraded with reduced efficiency compared with the CP receptor (PRA-V660) after induction with an agonist plus an antagonist (Fig. 7E). This effect was not observed with PRB (not shown). Taken together, these observations suggest that the different responses observed for the PR-L660 variant (both $A$ and $B$ isoforms) compared with the $\mathrm{CP}$ receptor, arise secondary to different post-translational modifications.

\section{The three-dimensional structures of PROGINS variant and $C P$ PR are different}

Different affinities of PR-V660 and PR-L660 proteins for kinases/phosphatases and components of the proteasomal degradation pathway may be related to different three-dimensional structures, which in turn may alter the accessibility of epitopes required for proteinprotein interactions. To check this hypothesis, we performed partial trypsin digestion assays (Fig. 8). The differences in the extent of trypsin digestions suggest that binding of progesterone (Fig. $8 \mathrm{~B}$ and $\mathrm{E}$ ) or RU486 (Fig. 8C and F) induces different 
A

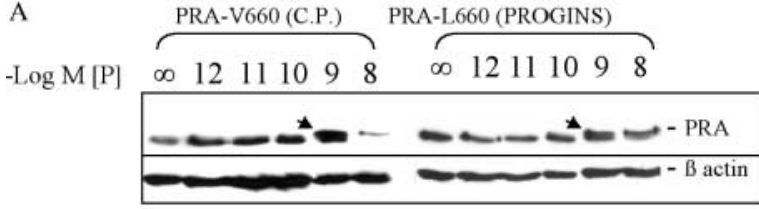

C

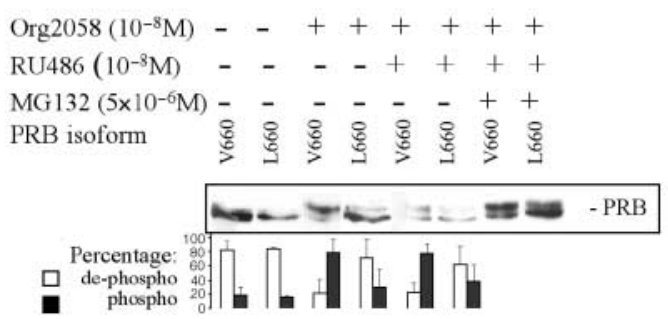

E

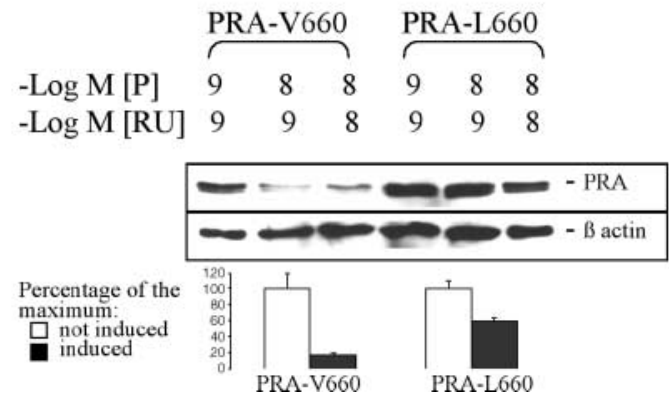

B

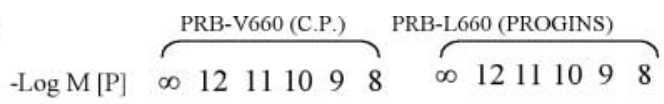

D

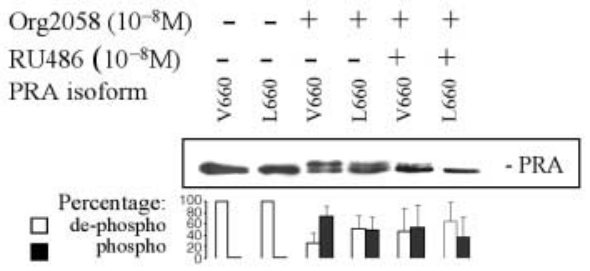

F

Figure 7 Phosphorylation and degradation of the PR V660 (CP) and L660 (PROGINS) variants. (A and B) Cell lines CHO-A25_2 and CHO-C4_3 (A) or cell lines CHO-B34 and CHO-D9_14 (B) were incubated with increasing concentrations of progesterone for $24 \mathrm{~h}$. PRA and PRB (both CP and PROGINS variants) become phosphorylated (arrowhead) upon ligand binding in a dose-dependent manner. Phosphorylated PRA or PRB can be distinguished because of their decreased electrophoretic mobility in SDS-PAGE compared with the non-phosphorylated forms. (C and D) Phosphorylation patterns of the PRB (C) and PRA (D), CP and PROGINS protein variants, after induction for $24 \mathrm{~h}$ with the indicated ligand combination. Phosphorylation patterns are more evident when cell lines are treated with MG132 $(5 \mu \mathrm{M}, 24 \mathrm{~h})$ to inhibit proteasomal degradation of PR. One representative western blot is shown. The charts at the bottom show the corresponding percentage of the dephospho and the phospho proteins observed in replicated western blot analyses. Mean values \pm s.D. are derived from three independent experiments. Total amount of PR per lane (phosphorylated + dephosphorylated forms) is fixed to 100. (E) Degradation of PRA-V660 and PRA-L660 after induction with different concentrations of progesterone $(P)$ plus RU486 (RU). The chart at the bottom represents the amount of PRA protein content (based on the intensity of bands visible in western blots and normalised with $\beta$-actin) after induction with the vehicle alone (empty bars, fixed to 100) or with progesterone plus RU486 (filled bars). Mean values \pm S.D. on at least two independent experiments. (F) To further clarify whether receptor proteins are phosphorylated into response ligand, cell extracts were treated with calf intestinal alkaline phosphatase (CIAP; $10 \mathrm{U}, 4 \mathrm{~h}$ ), which completely reverses the shift in molecular weight caused by phosphate(s) group(s) upon ligand binding.

three-dimensional conformations in PRA and PRB. Furthermore, the same stimulation conditions resulted in different degradation patterns of PR-V660 or PR-L660 variants for both A and B isoforms, suggesting that ligand-induced changes in the three-dimensional structures of PR-V660 and PR-L660 occur. In fact, in the absence of any induction, trypsin degradation of the PRA-L660 (PROGINS protein variant) is increased compared with PRA-V660 (Fig. 8A), whereas it is slightly reduced after incubation with progesterone (Fig. 8B) and unaffected after incubation with RU486 (Fig. 8C). PRB-L660 (PROGINS protein variant) appears to be less stable compared with the CP PR in the absence of any ligand or upon progesterone stimulation (Fig. 8D and E). By contrast, stimulation with RU486 only slightly reduces the stability of PRB-L660 compared with PRB-V660 (Fig. 8F).

\section{PRA CP and PROGINS protein variant mediate different cell proliferation responses}

The inhibitory effects of the progestin org2058 on the proliferation rate of cell lines stably expressing PRA-V660 (CHO-A25_2), PRA-L660 (CHO-C4_3), PRBV660 (CHO-B34) and PRB-L660 (CHO-D_14) were measured. Maternal cell line $\mathrm{CHO}-\mathrm{K} 1$ and cell line CHO-A21 (PR negative) were used as negative controls. In the absence of ligand, the cell line expressing PRA-V660 (CP) shows lower cell numbers compared with cell lines not expressing PR or cells expressing 

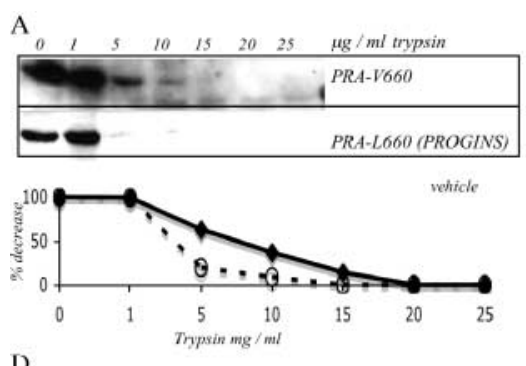

D

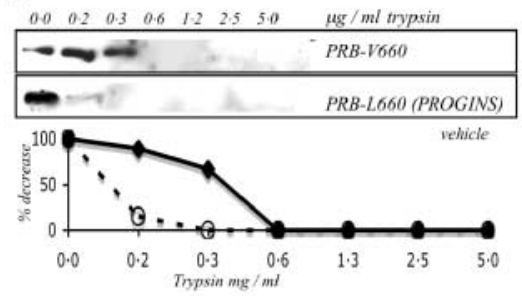

B
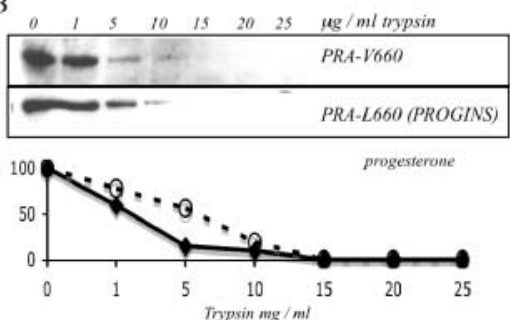

E

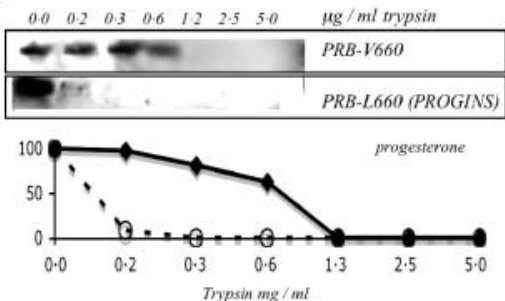

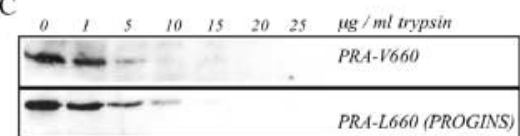

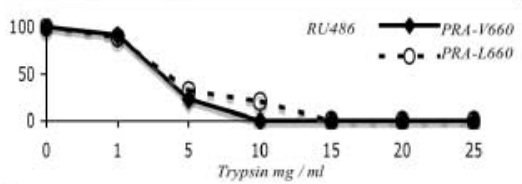

$\mathrm{F}$

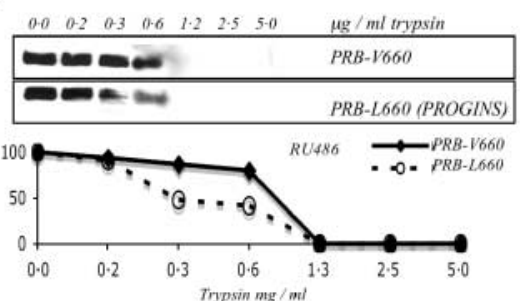

Figure 8 The sensitivity to trypsin partial digestion is different for PR V660 (CP) and L660 (PROGINS). (A-C) Degradation rates of PRA CP and PROGINS protein variant. (D-F) Degradation rates of PRB CP and PROGINS protein variant. Corresponding charts represent the quantification of western blot bands. Results from one experiment are shown. Results were confirmed in a second independent experiment.

PRA-L660 (PROGINS protein variant; Fig. 9A). Cells expressing PRA (either CP or PROGINS protein variant) also had reduced cell numbers in the presence of a PR agonist (org2058; Fig. 9B-C). However, in the presence of low concentration of the agonist org2058 $\left(10^{-10} \mathrm{M}\right.$; Fig. 9B), cells expressing PRA-V660 show a $12 \%$ reduction in total cell number compared with the response obtained in the absence of ligands. On the contrary, the same agonist concentration has no effect on the total cell number in cells expressing PRA-L660 (PROGINS protein variant); a 100-fold higher agonist concentration (org2058 10 $0^{-8}$ M; Fig. 9C) was required to obtain a similar (13\%) inhibition. To verify that the effects on total cell number were the result of diminished proliferative activity, the S-phase fractions were determined using BrdU incorporation and flow cytometry. BrdU incorporation in cells expressing PRA-V660 (CP) was reduced by treatment with org2058 $10^{-10} \mathrm{M}$ from $69 \cdot 6 \%$ (vehicle) to $55 \cdot 7 \%$, whereas in cells expressing PRA-L660 BrdU incorporation is reduced from $64.5 \%$ (vehicle) to $61.1 \%$ (org2058) only. No change in BrdU incorporation is seen in the PR-negative control cell line after org2058 treatment. After 24 and $36 \mathrm{~h}$ (not shown) of culture, BrdU incorporation reaches saturation.

In cells expressing PRB (either CP or PROGINS protein variant), total cell number was also reduced compared with the PR-negative cell cultures in the absence of any ligand. Treatment with org2058 reduced the total cell number. However, this inhibition never exceeded $5 \%$ compared with the treatment with vehicle alone and no difference is observed in the response of PRB-V660 or PRB-L660 (results not shown). Cells negative for the PR do not respond significantly to any treatment (Fig. 9A-D).
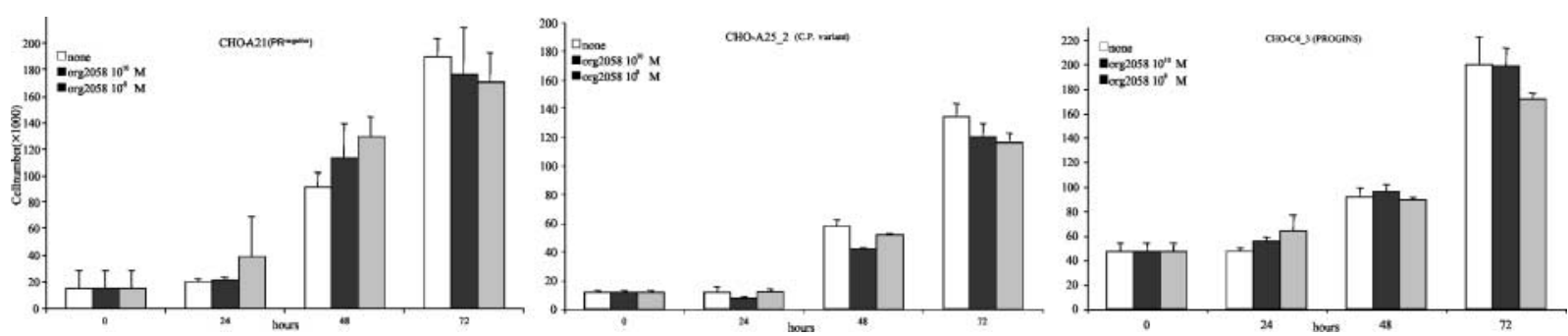

Figure 9 Different proliferative responses of the PRA-V660 or PRA-L660 in the presence of org2058. Cells stably transfected with PRA-V660 or PRA-L660 were cultivated in the presence of the vehicle (no induction) or in the presence of different concentrations of the agonist org2058 $\left(10^{-10}\right.$ and $\left.10^{-8} \mathrm{M}\right)$. An MTT assay was performed after different periods of growth $(0,24,48$ and $72 \mathrm{~h})$. Charts show results of one experiment: left panel, negative control (cells CHO-A21, PR negative); middle panel, cell expressing CP PRA (CHO-A25_2); right panel, cells expressing PROGINS PRA (CHO-C4_3). Mean values \pm S.D. are based on three to four measurements. Results were confirmed in three independent experiments. 

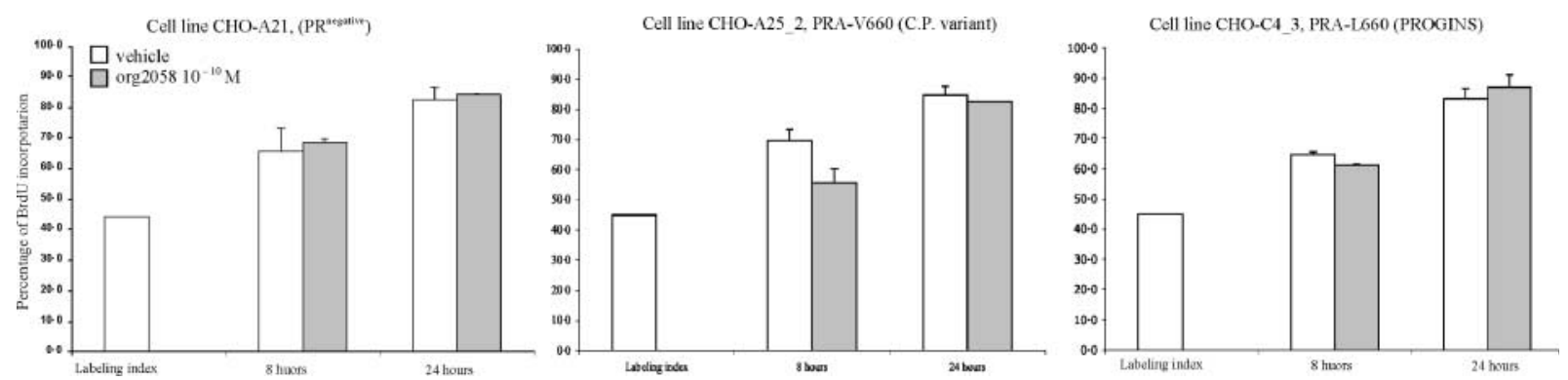

Figure $10 \mathrm{BrdU}$ incorporation. To assess proliferative activity, the S-phase fraction was determine by BrdU incorporation after stimulation with vehicle or org2058 $10^{-10} \mathrm{M}$ in cells stably expressing PR-V660 (CP; cells CHO-A25_2), PRA-L660 (PROGINS protein variant; cells $\mathrm{CHO}-\mathrm{C} 4 \_3$ ) and cells not expressing PR (CHO-A21). The number of BrdU labelled and unlabelled cells were determined by FACS analyses and the percentage is shown in the chart. Initial BrdU incorporation (labelling index) was measured 40 min after the addition of BrdU. Hormone stimulation was afterwards initiated and BrdU incorporation was measured at different periods of time ( 8 and $24 \mathrm{~h}$ ). After $36 \mathrm{~h}$ of incubation, incorporation was saturated (not shown).

\section{Discussion}

The net result of progesterone action depends on PR expression, local ligand metabolism, relative expression of PRA and PRB isoforms, cofactor binding and crosstalks with other signal transduction pathways ((Lanz et al. 1999, Beato \& Klug 2000, Shen et al. 2001, McKenna \& O’Malley 2002, Li \& O'Malley 2003, Qiu \& Lange 2003, Qiu et al. 2003) and see below). Subtle variations in $P R$ gene expression and protein activity affect the cellular response to progesterone. The human polymorphic variant PROGINS is a complex of three genetic aberrations (PV/HS-1 Alu insertion in intron $\mathrm{G}, \mathrm{V} 660 \mathrm{~L}$ and $\mathrm{H} 770 \mathrm{H}$ SNPs). Its prevalence is high (approximately 15\% in Caucasians) and it modulates the risk for several gynaecological disorders (Dunning et al. 1999, Lattuada et al. 2004, Modugno 2004, Schweikert et al. 2004, Pijnenborg et al. 2005, Romano et al. 2006). We showed in this study that the PV/HS-1 Alu insertion in intron G affects gene expression and RNA stability, whereas the V660L substitution reduces the response to progesterone. The effects of these genetic alterations were studied independently of each other. However, they lead to analogue consequences, and a possible combinatory effect of the PROGINS aberrations in vivo is speculated in the conclusions.

\section{Consequences of the PV/HS-1 Alu element in intron G of the PROGINS genetic variant}

Alu elements are human-specific transposable units present in approximately 1.4 million copies in the human genome (Deininger \& Batzer 2002, Deininger et al. 2003). They are retrotransposons that have amplified over the past 56 million years via a RNA intermediate transcribed by RNA Pol-III (Deininger $e t a l$.
2003) and it is estimated that in humans, Alu elements contribute to $0.1 \%$ of genetic diseases (Deininger \& Batzer 1999). Several functional consequences can be ascribed to the presence of Alu elements (Deininger \& Batzer 2002). Among these, Alus can influence gene transcription by modifying proximal promoter or distal enhancer. Owing to the high CpG content, Alus can lead to DNA methylation ((Deininger \& Batzer 1999) and references therein) and, in several cases, intronic Alus can be exonised (Lev-Maor et al. 2003, Sorek et al. 2004) leading to the generation of splice variants.

We have investigated whether the Alu insertion in intron G (PROGINS polymorphic variant) affects the transcription rate and RNA maturation due to (a) CpG methylation, (b) modification of transcription factorbinding sites, (c) affecting RNA stability and d) the generation of splice variants.

Although the PROGINS allele in T47D cells is transcribed with reduced efficiency compared with the CP PR (Figs 4A, lane 5 and 4C), this is not caused by methylation of the PROGINS-Alu because treatment with a DNA demethylating agent (ADC) does not increase its transcription. Furthermore, reduced transcription of the PROGINS allele appears not to be a general phenomenon, because cDNA-PCR-RFLP based screening on mRNA isolated from human endometrium of fertile healthy women showed that the PROGINS and the CP alleles are expressed at comparable levels (A Romano unpublished). Even if transcription of the PROGINS allele is not modified by DNA methylation, it is increased by $17 \beta$-oestradiol upon ER- $\alpha$ activation and subsequent binding, together with the Sp1 transcription factor, to the Alu-ERE/Sp1 site. Similar cases have been reported in literature. Norris et al. (1995) have shown that the BRCA-1 gene responds to oestrogen because of an Alu element containing an imperfect ERE, which is responsible for ER$\alpha$ binding. The half-ERE/Sp1 site in the promoter of the $P R$ gene induces its transcription in response to 
oestrogens (Petz \& Nardulli 2000). Furthermore, Sp1 and ER- $\alpha$ can bind to DNA sequences located in proximal promoter and in distal enhancers (Norris et al. 1995, Bouwman \& Philipsen 2002, Carroll et al. 2005, Goffin et al. 2005) and the binding of ER- $\alpha$ to 'non-canonical' half-ERE is more common than until recently expected (Carroll et al. 2005).

Once transcribed by the RNA Pol-III, individual Alu-RNAs belonging to different families generate molecules with different stabilities (Aleman et al. 2000, Li \& Schmid 2004). However, the effect that Alus have on the stability of (pre)-mRNA of those genes in which they are integrated (transcribed by the RNA Pol-II), has not been studied. We observed that the transcript derived from the PROGINS allele is less stable compared with the transcript derived from the $\mathrm{CP}$ allele, both in native T47D cells and in cells transfected with minigenes (Fig. 5). RNA decay pathways are controlled by RNAprotein complexes that assemble at specific sites on the target transcripts (Lemaire et al. 2002, Meisner et al. 2004, Huang \& Steitz 2005, Moore 2005). For example, Lemaire et al. (2002) have shown that SR proteins (a family of splicing factors) can reduce the stability of the mRNA molecules by binding to purine-rich regions in the $3^{\prime} \mathrm{UTR}$. A purine-rich region is present in Alu elements, and, although the PROGINS Alu is not located in the $3^{\prime} \mathrm{UTR}$, it is still very proximal to it. Alternatively, Alus transcribed by RNA Pol-III (in their sense orientation) could pair with the PROGINS Alu, which is transcribed by RNA Pol-II in the pre-mRNA-Alu as its anti-sense sequence (Fig. 2A), and trigger dsRNAmediated degradation. In our experiments, the reduced stability of the PROGINS transcript compared with the CP pre-mRNA is more pronounced in native T47D cells than in cells transfected with the minigenes (Fig. 5). This can be explained by the presence of specific enzymatic mechanisms leading to pre-mRNA-Alu degradation. Probably, transient transfection triggers higher RNA transcription in a few cells, thereby saturating the RNA degradation machinery in these cells.

Following pre-mRNA transcription, intronic Alus can generate alternative splice variants (Alu 'exonisation' (Deininger \& Batzer 1999, Deininger et al. 2003, Lev-Maor et al. 2003, Sorek et al. 2004)). The $3^{\prime}$ and $5^{\prime}$ sites (shown in Fig. 2B) for alternate and constitutive 'exonisation' of Alus have been exhaustively studied by one group (Lev-Maor et al. 2003, Sorek et al. 2004). According to these studies, the PROGINS Alu is not expected to generate 'exonised' splice variants. Nevertheless, flanking sequences can influence alternate splicing (e.g. the branching site for the Alu 'exonisation' is located in the region of gDNA flanking the putative $3^{\prime}$ splice site of the Alu). According to our results, the generation of any splice variants by the PROGINS Alu insertion can be excluded.

\section{Consequences of the SNP-G3432T in exon 4 causing the amino acid substitution (V660L)}

It is plausible that the translation efficiency of the PROGINS transcript is reduced by sub-optimal codon usage for leucine-660 in the PROGINS variant. The PROGINS leucine-660 is coded by TTG with a preference of approximately $11 \%$, which is much lower than the $42 \%$ preference of the optimal codon for leucine, CTG (Zhao et al. 2003).

\section{Consequences of the protein V660L substitution}

The V660L substitution is located in the hinge region of the receptor, i.e. the region between the DBD and the LBD. So far, no specific function has been ascribed to the hinge region and it may be involved in nuclear translocation, receptor dimerisation in solution, protein stability and cofactor interaction (Jackson et al. 1997, Tetel et al. 1997, Li \& O'Malley 2003). Our preliminary investigations indicate that the V660L substitution does not affect translocation of PRA and PRB to the nucleus (results not shown).

Agoulnik et al. (2004) have described an increased transactivation activity of PR-L660 (PROGINS protein variant) on a GRE2-E1b-CAT reporter in COS-1 cells. We have extended these studies and present evidence that the net activity of PR-V660 (CP) and PR-L660 (PROGINS) variant varies in a cell- and liganddependent manner. The transactivation activity on the MMTV-luciferase reporter induced by PR-L660 (PROGINS protein variant) compared with the CP PR-V660 (both A and B isoforms) is reduced only in Skov-3 cells and in cells stably transfected with PRA (CHO-A25_2 and CHO-C4_3) and PRB (CHO-B34 and CHOD9_14). Interestingly, these cells are of ovarian origin (human and hamster), and epidemiological studies indicate that the PROGINS allele might increase the risk for ovarian cancer (see below). Transrepression of PRA on PRB and of PR on ER- $\alpha$ is not influenced by the V660L substitution.

\section{Different responses of the CP and PROGINS PR are a consequence of different post-translational modifi- cations of the proteins}

PR is subjected to several post-translational modifications. It contains 18 serines as potential phosphorylation sites and at least seven residues are phosphorylated in vivo (Knotts et al. 2001). Bagchi et al. (1992) have classified two types of phosphorylation sites. Fast phosphorylation sites, that are basally phosphorylated (without PR induction) and their phosphorylation increases upon ligand binding within minutes (ser-81, ser-162 present only in PRB, ser-190 and ser-400), and slow phosphorylation sites, that 
become phosphorylated in a ligand-dependent manner within a few hours after induction (ser-102 present only in PRB, ser-294 and ser-345). Although the activity of PR is controlled by the activating functions (AFs) in the LBD and in the N-terminal domain (unaffected by the V660L substitution), its fine regulation is influenced by phosphorylation (Bagchi et al. 1992, Takimoto et al. 1996, Weigel 1996, Knotts et al. 2001, Qiu \& Lange 2003, Qiu et al. 2003, Pierson-Mullany \& Lange 2004), protein degradation (Lange et al. 2000, Shen et al. 2001) and other post-translational modifications.

We have shown that the activity of the PROGINS protein variant compared with the cognate CP PR depends on the cellular context. Considering that the expression of kinases and proteasomal components is closely related to the cellular context, we hypothesised that this could determine the different actions of the two PR variants. Here, we show that PR CP and PROGINS protein variant become phosphorylated with similar efficiency within a few minutes after induction with a ligand (fast phosphorylation sites). By contrast, phosphorylation of the late phospho residues, examined $24 \mathrm{~h}$ after induction, occurs with reduced efficiency in the PROGINS protein variants (both PRA and PRB isoforms; Fig. 7) compared with the CP PR. PRA-L660 (PROGINS protein variant) also shows minor protein degradation compared with PRA-V660 when induced with the combination of agonist and antagonist. Interestingly, some authors have described that PR phosphorylation and subsequent degradation by proteasomal machinery determine a hyperactivity of the receptor (Lange et al. 2000, Shen et al. 2001). It could be thus speculated that in the presence of the PROGINS protein variant this mechanism is impaired due to incomplete phosphorylation and protein degradation.

\section{PROGINS protein variant and CP PR have different three-dimensional structures}

The activity of PR is regulated by conformational changes that, upon ligand binding, facilitate the formation of binding pockets for specific co-activators, kinases and other interacting proteins (Tanenbaum et al. 1998, Williams \& Sigler 1998, Madauss et al. 2004). Trypsin sensitivity assays show that different conformational changes occur in PR upon binding to an agonist or to an antagonist and that these changes vary between PR CP and PROGINS protein variant (Fig. 8). Thus, differential post-translational modifications between the CP PR and the PROGINS protein variant probably arise from different three-dimensional structures of the two proteins. Secondary structure probability prediction (http://bmerc-www.bu.edu; Biomolecular Engineering Research Centre, Boston University, MA, USA) suggests that the residue 660 is located in a 7-residue loop (657PQPV/LGVP-663) between two $\alpha$-helices that are connected to the DBD and the LBD. The high conservation among species (mouse, rabbit, sheep, rat and human) of this 7-residue loop (Clustal-W analysis, http:/ / www.ru.nl; Centre for Molecular and Biomolecular Informatics, Nijmegen University, The Netherlands) and particularly of the Val-660, indicates its importance for protein functionality. Although valine and leucine have similar chemical properties, they differ sterically (valine is a $\beta$-branched small amino acid, whereas leucine is a $\gamma$-branched medium-sized amino acid). Substituting a small $\beta$-branched residue in a loop with a larger $\gamma$-branched residue might influence the angle and the flexibility of the loop, affecting the conformation of PR at the level of the secondary structure (locally in the folding of the hinge region) or at the level of the ultrasecondary structure, i.e. in positioning the DBD with respect to the LBD. The flexibility of the hinge region is crucial to accommodate the relative position of DBD and LBD for other nuclear receptors (Mangelsdorf et al. 1995, Tetel et al. 1997).

\section{PR-PROGINS protein variant is less efficient than the CP PR in opposing cell proliferation}

Progesterone is the natural antagonist of oestradiolinduced proliferation in the endometrium (Lydon et al. 1995) and reduces cell proliferation in the ovarian epithelium (Ho 2003, Syed \& Ho 2003). We tested whether the reduced transactivation activity of PR-L660 is translated into reduced biological activity, i.e. reduced cellular proliferation. This is indeed the case. In ovarian cell lines stably expressing the PRA-L660 (PROGINS protein variant), the inhibition of basal cell proliferation is less pronounced compared with cells expressing the PRA CP (Figs 9 and 10). This difference was not seen for PRB (results not shown). This is in line with the observations in PRA and PRB null mice (KO; Lydon et al. 1995) or PRA-KO and PRB-KO mice (Chappell et al. 1997, Mulac-Jericevic et al. 2000, 2003, Conneely et al. 2003) showing that PRA, but not PRB, mediates all major actions of progesterone in the endometrium and in the ovary. In the mammary gland, however, progesteronemediated regulation of proliferation is mediated by PRB.

\section{Conclusions}

Our characterisation of the PROGINS polymorphic variant clearly indicates that both PROGINS aberrations can cause a reduced action of progestins in the presence of PROGINS PR compared with the CP PR. We observed (a) reduced stability of the PR-PROGINS transcripts, (b) reduced transactivation activity of the PROGINS variant and (c) less efficient inhibition of cell proliferation in ovarian cells expressing the PROGINS variant of PRA. Interestingly, epidemiological studies indicated that 
women carrying the PROGINS allele are at increased risk to develop pathologies at those sites for which progesterone exposure has a protective action like ovarian cancer, endometrial cancer and endometriosis (Ho 2003, Syed \& Ho 2003, Lattuada et al. 2004, Modugno 2004, Pijnenborg et al. 2005, Romano et al. 2006). In breast, however, where progesterone exposure does not protect against tumour development but rather induces cell proliferation, PROGINS carriers are at reduced risk to develop breast cancer (Dunning et al. 1999).

\section{Acknowledgements}

The authors would like to thank Prof. Schuele for MMTV-luciferase construct, Dr Agoulnik for PR expression plasmids Alberto Gatti for precious technical help. The authors would like to thank Dr Xanthoulea and Dr Voncken, Department of Molecular Genetics for critically reading this manuscript. They are also grateful to Dr Schutte, Mieke Henfling and Caroline Jaemers, Department of Molecular and Cellular Biology for helping with the BrdU incorporation and the FACS analyses. The authors declare that there is no conflict of interest that would prejudice the impartiality of this scientific work.

\section{References}

Agoulnik IU, Tong XW, Fischer DC, Korner K, Atkinson NE, Edwards DP, Headon DR, Weigel NL \& Kieback DG 2004 A germline variation in the progesterone receptor gene increases transcriptional activity and may modify ovarian cancer risk. Journal of Clinical Endocrinology and Metabolism 89 6340-6347.

Aleman C, Roy-Engel AM, Shaikh TH \& Deininger PL 2000 Cis-acting influences on Alu RNA levels. Nucleic Acids Research 28 4755-4761.

Bagchi MK, Tsai SY, Tsai MJ \& O’Malley BW 1992 Ligand and DNAdependent phosphorylation of human progesterone receptor in vitro. PNAS 89 2664-2668.

Beato M \& Klug J 2000 Steroid hormone receptors: an update. Human Reproduction Update 6 225-236.

Bouwman P \& Philipsen S 2002 Regulation of the activity of Sp1related transcription factors. Molecular and Cellular Endocrinology 195 27-38.

Carroll JS, Liu XS, Brodsky AS, Li W, Meyer CA, Szary AJ, Eeckhoute J, Shao W, Hestermann EV, Geistlinger TR et al. 2005 Chromosomewide mapping of estrogen receptor binding reveals long-range regulation requiring the forkhead protein FoxA1. Cell 122 33-43.

Chappell PE, Lydon JP, Conneely OM, O'Malley BW \& Levine JE 1997 Endocrine defects in mice carrying a null mutation for the progesterone receptor gene. Endocrinology 138 4147-4152.

Conneely OM, Mulac-Jericevic B \& Lydon JP 2003 Progesteronedependent regulation of female reproductive activity by two distinct progesterone receptor isoforms. Steroids 68 771-778.

Dammann R, Yang G \& Pfeifer GP 2001 Hypermethylation of the cpG island of Ras association domain family 1A (RASSF1A), a putative tumor suppressor gene from the 3 p21.3 locus, occurs in a large percentage of human breast cancers. Cancer Research 61 3105-3109.
De Vivo I, Huggins GS, Hankinson SE, Lescault PJ, Boezen M, Colditz GA \& Hunter DJ 2002 A functional polymorphism in the promoter of the progesterone receptor gene associated with endometrial cancer risk. PNAS 99 12263-12268.

Deininger PL \& Batzer MA 1999 Alu repeats and human disease. Molecular Genetics and Metabolism 67 183-193.

Deininger PL \& Batzer MA 2002 Mammalian retroelements. Genome Research 12 1455-1465.

Deininger PL, Moran JV, Batzer MA \& Kazazian HH Jr 2003 Mobile elements and mammalian genome evolution. Current Opinion in Genetics and Development 13 651-658.

Dunning AM, Healey CS, Pharoah PD, Teare MD, Ponder BA\& Easton DF 1999 A systematic review of genetic polymorphisms and breast cancer risk. Cancer Epidemiology, Biomarkers and Prevention 8 843-854.

Gibbons R \& Dugaiczyk A 2005 Phylogenetic roots of Alu-mediated rearrangements leading to cancer. Genome 48 160-167.

Goffin V, Demonte D, Vanhulle C, de Walque S, de Launoit Y, Burny A, Collette Y \& Van Lint C 2005 Transcription factor binding sites in the pol gene intragenic regulatory region of HIV-1 are important for virus infectivity. Nucleic Acids Research 33 4285-4310.

Ho SM 2003 Estrogen, progesterone and epithelial ovarian cancer. Reproductive Biology and Endocrinology 173.

Huang Y \& Steitz JA 2005 SRprises along a messenger's journey. Molecular Cell 17 613-615.

Jackson TA, Richer JK, Bain DL, Takimoto GS, Tung L \& Horwitz KB 1997 The partial agonist activity of antagonist-occupied steroid receptors is controlled by a novel hinge domain-binding coactivator L7/SPA and the corepressors N-CoR or SMRT. Molecular Endocrinology 11 693-705.

Knotts TA, Orkiszewski RS, Cook RG, Edwards DP \& Weigel NL 2001 Identification of a phosphorylation site in the hinge region of the human progesterone receptor and additional amino-terminal phosphorylation sites. Journal of Biological Chemistry 276 8475-8483.

Lange CA, Shen T \& Horwitz KB 2000 Phosphorylation of human progesterone receptors at serine-294 by mitogen-activated protein kinase signals their degradation by the $26 \mathrm{~S}$ proteasome. PNAS $\mathbf{9 7}$ 1032-1037.

Lanz RB, McKenna NJ, Onate SA, Albrecht U, Wong J, Tsai SY, Tsai MJ \& O'Malley BW 1999 A steroid receptor coactivator, SRA, functions as an RNA and is present in an SRC-1 complex. Cell 97 17-27.

Lattuada D, Somigliana E, Vigano P, Candiani M, Pardi G \& Di Blasio AM 2004 Genetics of endometriosis: a role for the progesterone receptor gene polymorphism PROGINS? Clinical Endocrinology (Oxf) 61 190-194.

Lemaire R, Prasad J, Kashima T, Gustafson J, Manley JL \& Lafyatis R 2002 Stability of a PKCI-1-related mRNA is controlled by the splicing factor ASF/SF2: a novel function for SR proteins. Genes and Development 16 594-607.

Lev-Maor G, Sorek R, Shomron N \& Ast G 2003 The birth of an alternatively spliced exon: 3' splice-site selection in Alu exons. Science 300 1288-1291.

Li X \& O'Malley BW 2003 Unfolding the action of progesterone receptors. Journal of Biological Chemistry 278 39261-39264.

Li TH \& Schmid CW 2004 Alu's dimeric consensus sequence destabilizes its transcripts. Gene 324 191-200.

Lydon JP, DeMayo FJ, Funk CR, Mani SK, Hughes AR, Montgomery CA Jr, Shyamala G, Conneely OM \& O'Malley BW 1995 Mice lacking progesterone receptor exhibit pleiotropic reproductive abnormalities. Genes and Development 9 2266-2278.

Madauss KP, Deng SJ, Austin RJ, Lambert MH, McLay I, Pritchard J, Short SA, Stewart EL, Uings IJ \& Williams SP 2004 Progesterone receptor ligand binding pocket flexibility: crystal structures of the norethindrone and mometasone furoate complexes. Journal of Medicinal Chemistry 47 3381-3387.

Mangelsdorf DJ, Thummel C, Beato M, Herrlich P, Schutz G, Umesono K, Blumberg B, Kastner P, Mark M, Chambon P et al. 1995 The nuclear receptor superfamily: the second decade. Cell 83 835-839. 
McKenna NJ \& O'Malley BW 2002 Minireview: nuclear receptor coactivators - an update. Endocrinology 143 2461-2465.

Meisner NC, Hackermuller J, Uhl V, Aszodi A, Jaritz M \& Auer M 2004 mRNA openers and closers: modulating AU-rich element-controlled mRNA stability by a molecular switch in mRNA secondary structure. Chembiochem 5 1432-1447.

Modugno F 2004 Ovarian cancer and polymorphisms in the androgen and progesterone receptor genes: a HuGE review. American Journal of Epidemiology 159 319-335.

Moore MJ 2005 From birth to death: the complex lives of eukaryotic mRNAs. Science 309 1514-1518.

Mulac-Jericevic B, Mullinax RA, DeMayo FJ, Lydon JP \& Conneely OM 2000 Subgroup of reproductive functions of progesterone mediated by progesterone receptor-B isoform. Science $\mathbf{2 8 9}$ 1751-1754

Mulac-Jericevic B, Lydon JP, DeMayo FJ \& Conneely OM 2003 Defective mammary gland morphogenesis in mice lacking the progesterone receptor B isoform. PNAS 100 9744-9749.

Muller JM, Isele U, Metzger E, Rempel A, Moser M, Pscherer A, Breyer T, Holubarsch C, Buettner R \& Schule R 2000 FHL2, a novel tissuespecific coactivator of the androgen receptor. EMBO Journal 19 359-369.

Norris J, Fan D, Aleman C, Marks JR, Futreal PA, Wiseman RW, IglehartJD, Deininger PL \& McDonnell DP 1995 Identification of a new subclass of Alu DNA repeats which can function as estrogen receptordependent transcriptional enhancers. Journal of Biological Chemistry 270 22777-22782.

Petz LN \& Nardulli AM 2000 Sp1 binding sites and an estrogen response element half-site are involved in regulation of the human progesterone receptor A promoter. Molecular Endocrinology 14 972-985.

Pierson-Mullany LK \& Lange CA 2004 Phosphorylation of progesterone receptor serine 400 mediates ligand-independent transcriptional activity in response to activation of cyclin-dependent protein kinase 2. Molecular and Cellular Biology 24 10542-10557.

Pijnenborg JM, Romano A, Dam-de Veen GC, Dunselman GA, Fischer DC, Groothuis PG \& Kieback DG 2005 Aberrations in the progesterone receptor gene and the risk of recurrent endometrial carcinoma. Journal of Pathology 205 597-605.

Qiu M \& Lange CA 2003 MAP kinases couple multiple functions of human progesterone receptors: degradation, transcriptional synergy, and nuclear association. Journal of Steroid Biochemistry and Molecular Biology 85 147-157.

Qiu M, Olsen A, Faivre E, Horwitz KB \& Lange CA 2003 Mitogenactivated protein kinase regulates nuclear association of human progesterone receptors. Molecular Endocrinology 17 628-642.

Richer JK, Jacobsen BM, Manning NG, Abel MG, Wolf DM \& Horwitz KB 2002 Differential gene regulation by the two progesterone receptor isoforms in human breast cancer cells. Journal of Biological Chemistry 277 5209-5218.

Romano A, Lindsey PJ, Fischer DC, Delvoux B, Paulussen AD, Janssen RG \& Kieback DG 2006 Two functionally relevant polymorphisms in the human progesterone receptor gene ( $+331 \mathrm{G} /$ A and progins) and the predisposition for breast and/or ovarian cancer. Gynecologic Oncology 101 287-295

Rowe SM, Coughlan SJ, McKenna NJ, Garrett E, Kieback DG, Carney DN \& Headon DR 1995 Ovarian carcinoma-associated TaqI restriction fragment length polymorphism in intron $\mathrm{G}$ of the progesterone receptor gene is due to an Alu sequence insertion. Cancer Research $\mathbf{5 5}$ 2743-2745.

Schutte B, Nieland L, van Engeland M, Henfling ME, Meijer L \& Ramaekers FC 1997 The effect of the cyclin-dependent kinase inhibitor olomoucine on cell cycle kinetics. Experimental Cell Research 236 4-15.

Schweikert A, Rau T, Berkholz A, Allera A, Daufeldt S \& Wildt L 2004 Association of progesterone receptor polymorphism with recurrent abortions. European Journal of Obstetrics, Gynecology, and Reproductive Biology 113 67-72.

Shang Y, Hu X, DiRenzo J, Lazar MA \& Brown M 2000 Cofactor dynamics and sufficiency in estrogen receptor-regulated transcription. Cell 103 843-852.

Shen T, Horwitz KB \& Lange CA 2001 Transcriptional hyperactivity of human progesterone receptors is coupled to their ligand-dependent down-regulation by mitogen-activated protein kinase-dependent phosphorylation of serine 294. Molecular and Cellular Biology 21 6122-6131.

Sorek R, Lev-Maor G, Reznik M, Dagan T, Belinky F, Graur D \& Ast G 2004 Minimal conditions for exonization of intronic sequences: $5^{\prime}$ splice site formation in alu exons. Molecular Cell 14 221-231.

Syed V \& Ho SM 2003 Progesterone-induced apoptosis in immortalized normal and malignant human ovarian surface epithelial cells involves enhanced expression of FasL. Oncogene 22 6883-6890.

Takimoto GS, Hovland AR, Tasset DM, Melville MY, Tung L \& Horwitz KB 1996 Role of phosphorylation on DNA binding and transcriptional functions of human progesterone receptors. Journal of Biological Chemistry 271 13308-13316.

Tanenbaum DM, Wang Y, Williams SP \& Sigler PB 1998 Crystallographic comparison of the estrogen and progesterone receptor's ligand binding domains. PNAS 95 5998-6003.

Tetel MJ, Jung S, Carbajo P, Ladtkow T, Skafar DF \& Edwards DP 1997 Hinge and amino-terminal sequences contribute to solution dimerization of human progesterone receptor. Molecular Endocrinology 11 1114-1128.

Wang-Gohrke S, Chang-Claude J, Becher H, Kieback DG \& Runnebaum IB 2000 Progesterone receptor gene polymorphism is associated with decreased risk for breast cancer by age 50. Cancer Research 60 2348-2350.

Weigel NL 1996 Steroid hormone receptors and their regulation by phosphorylation. Biochemical Journal 319 657-667.

Williams SP \& Sigler PB 1998 Atomic structure of progesterone complexed with its receptor. Nature 393 392-396.

You Z, Fischer DC, Tong X, Hasenburg A, Aguilar-Cordova E \& Kieback DG 2001 Coxsackievirus-adenovirus receptor expression in ovarian cancer cell lines is associated with increased adenovirus transduction efficiency and transgene expression. Cancer Gene Therapy 8 168-175.

Received in final form 16 October 2006

Accepted 26 October 2006

Made available online as an Accepted Preprint 17 November 2006 